Journal of Sustainable Agricultural Sciences
http://jsas.journals.ekb.eg/

(1) معارف العاملين الإشاديين بأنثطنهم الإتصالية بححافظة كفر الثيخ

عادل إبراهيم محمد الحامولي"، أحمد مصطفي عبد الله، عبدالعليم سيد أحمد الثافعي وعزت محمد مجاهد

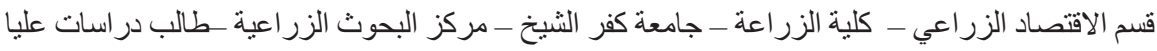

استهدف البحث بصفة رئيسية التعرف علي درجة معارف العاملين الإرشاديين بأنشطتهم الإتصالية بمحافظة

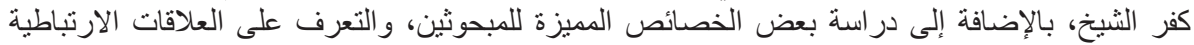

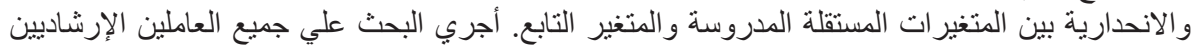

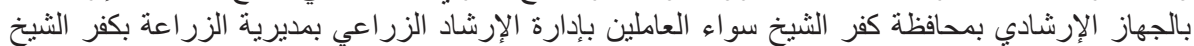

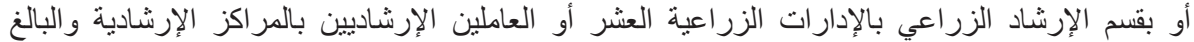

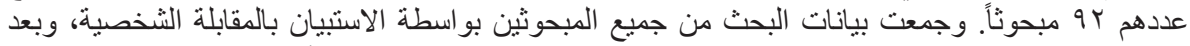

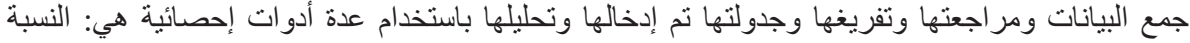

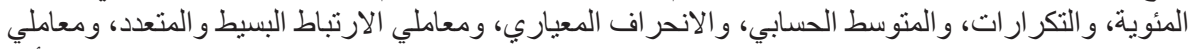

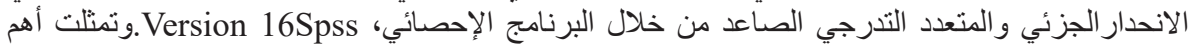

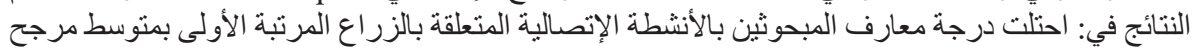

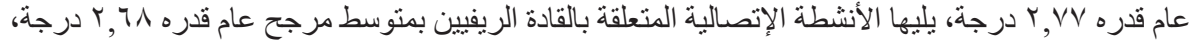

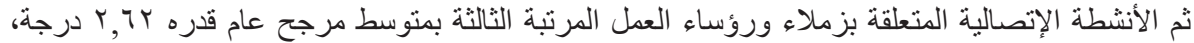

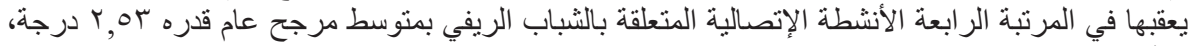

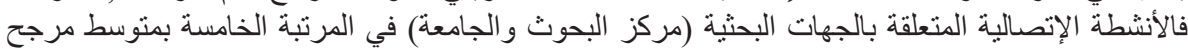

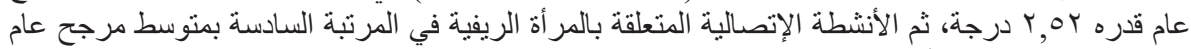

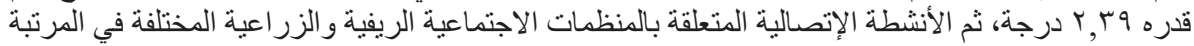

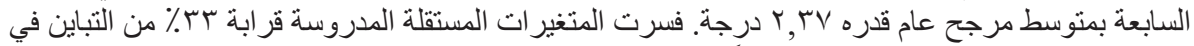

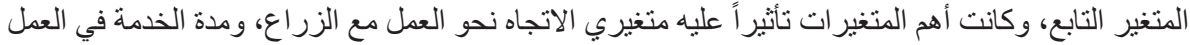
الإرشادي.

الكلمات المفتاحية: المعرفة، الأنشطة، الإتصال ،الزراع، القادة الريفيين، المنظمات.

السمكية، و الرعاية البيطرية، و والتوعية السكانية، و التغذية،

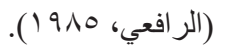

ويمثل التقدم العلمي الكبير والمستمر في كافة المجالات

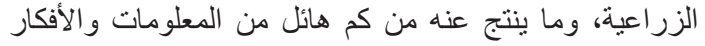

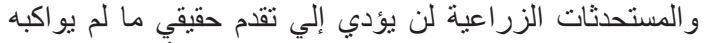

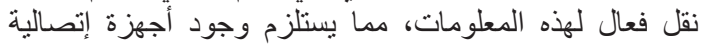

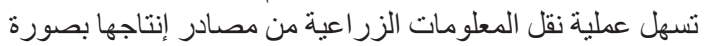

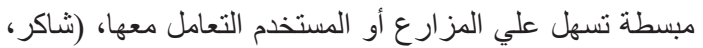
. (r... r

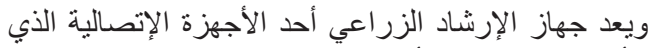

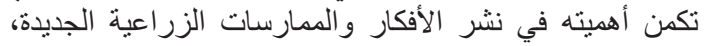

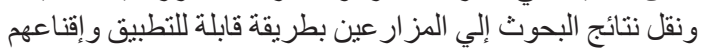

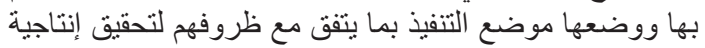

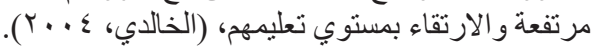

المقدمة ومشكلة البحث

تعتمد عملية تنمية وتحديث القطاع الزر اعي المصري اعتماداً

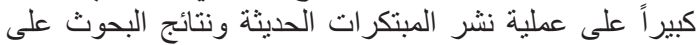

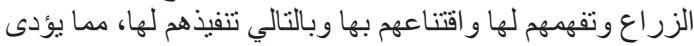

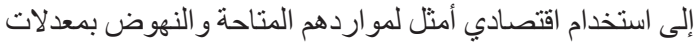

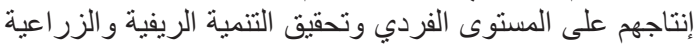

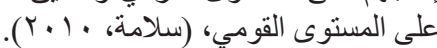

ويعتبر الإرشاد الزراعي ضمن أبرز أجهزة التنمية الريفية

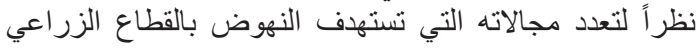

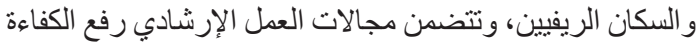

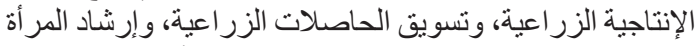

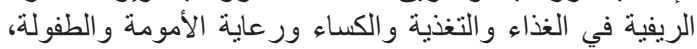

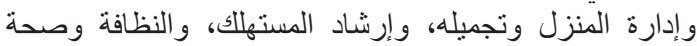

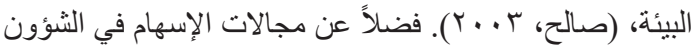
العامة والحفاظ علي البيئة الريفية وترشيد مياه الري، والثين الثروة الثون 
الفعال), وبهذا التعريف يكون التركيز على العمل أو الأداء الفعال

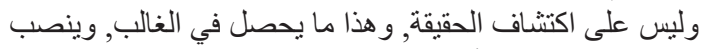

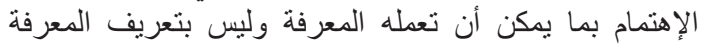

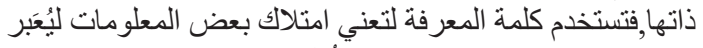

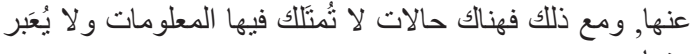
عن

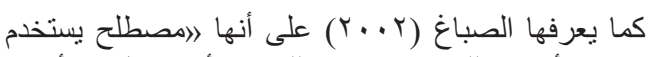

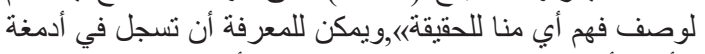

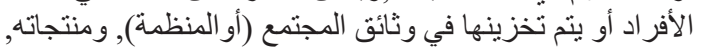

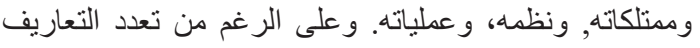

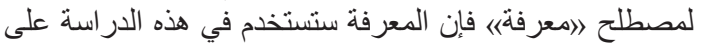

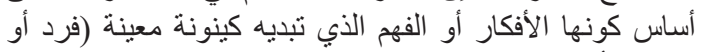

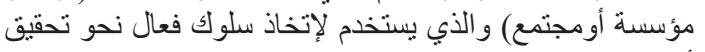

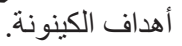

ويري عمر وآخرون (9VT (1) أن هنالك ثلاثة أنواع من المعارف يتضمنها أي برنامج تعليمي وهي:

1

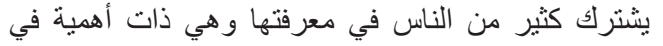

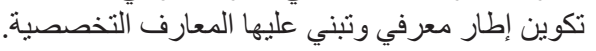

r- معارف تخصصية: وهي مجموعة المعلومات المتخصصة

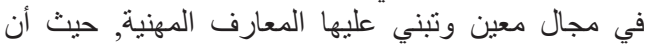

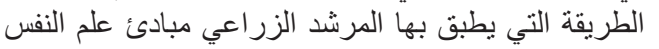
تختلف عن طريقة تطبيق عالم النفس لتلأك المبادئ.

r- معارف مهنيـة: وهي معارف ذات طبيعة معينة لأنها

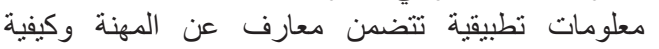
ممارستها وخصائصها كما أنها تساعد علي تطبيق تصنيق المعارف

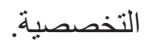

بينما يري سيد أحمد ( 99 (1) أن معظم الباحثنين قَسَموا المعرفـة إلي ثلاثة أقسام وهي: أحمي:

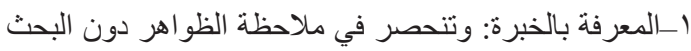

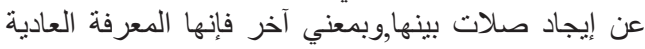
اليومية القائمة علي الخبرة و المران.

r-المعرفة الفلسفية: وهي المرحلة التالية من مراحل التفكير

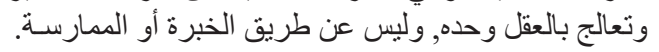

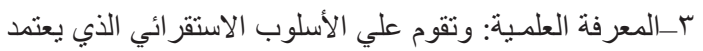

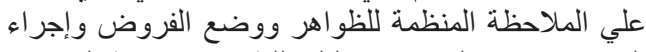

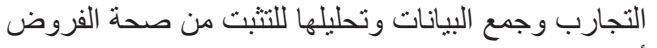
أو بطلانها.

ويصنف نوناكا وتاكوشي (1990) المعرفة حسب إدارتها إلى صنفين هما:

ا ـالمعرفة الصريحة Explicit Knowledge: وهي المعرفة المنظمة المحدودة المحتوى التي تتصف بالمبن بالمظاهر الخارجية

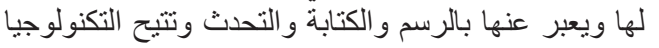
تحويلها وتناقلها.

r-المعرفة الضمنية Tacit Knowledge: وهي المعرفة القاطنة في عقول وسلوك الأفراد, وهي تثشير إلى الحس

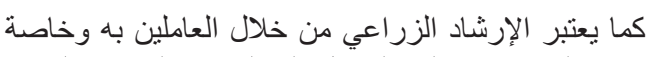

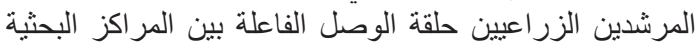

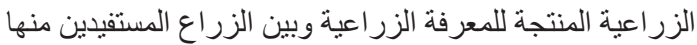

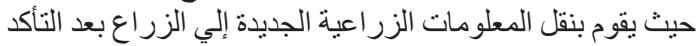

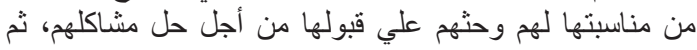

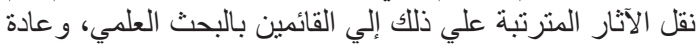

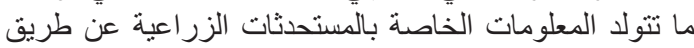

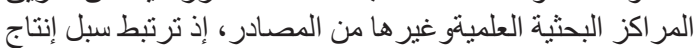

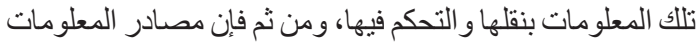

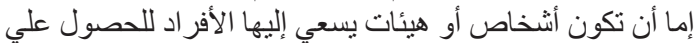
معلوماتهم، (عبد المقصود،، 911 (1) ).

ويعتمد الإرشاد الزراعي في عملياته الإتصالية لتنفيذ

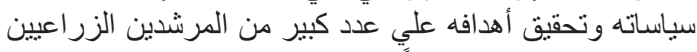

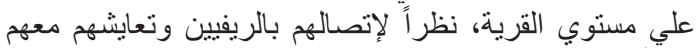

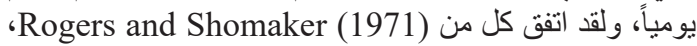

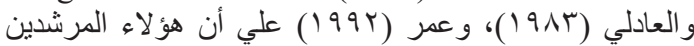

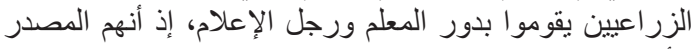

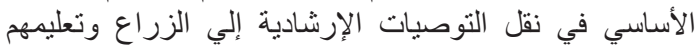

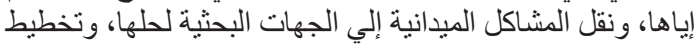

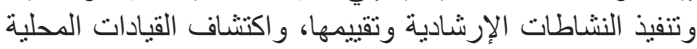
وتدريبها، وتحقيق التعاون والتنسيق مع المنظمات الاجتمانية واتفية

الريفية.

و وتتأثر عملية نقل التوصيات و التقنيات الزر اعية المستحدثة

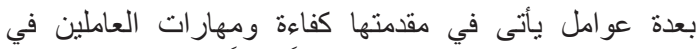

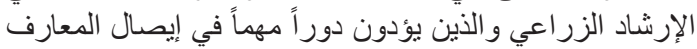

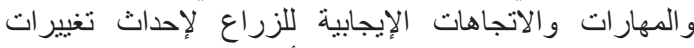

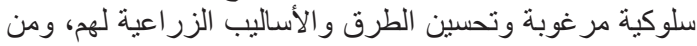

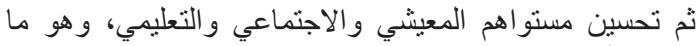

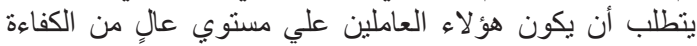

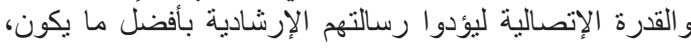

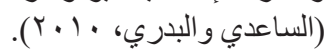

وبناء علي ما سبق يمكن بلورة مشكلة البحث في الأسئلة التالية: ما درجة معارف العاملين الإرشاديين بالأنشطة الإتصالية الإنها

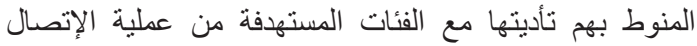

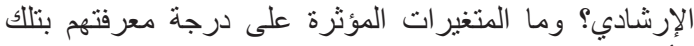

الأنشطة الاتصالية؟

أهداف البحث

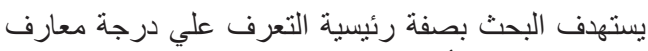
العاملين الإرشاديين بأنشطتهم الإتصالية بمحافظة البرفة كفر الثيخ،

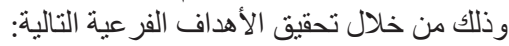

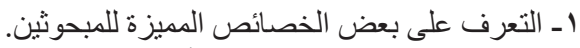

r ـ ت ـ التحديد درجة معارف بع المبحوثين بأنشطتهم الإتصالية.

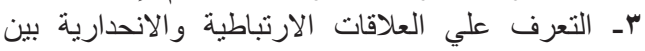

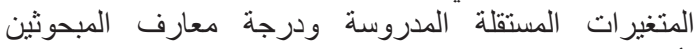
بأنشطنهم الإتصالية.

الاستعر اض المرجعي

يري بدير (919 199) أن المعرفة هي (احصيلة من الحقائق

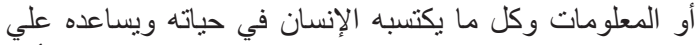

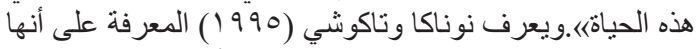

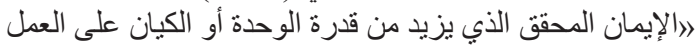


قد تكون مما نتلقاها عن الآخرين أو مما نلاحظها أو نحصل

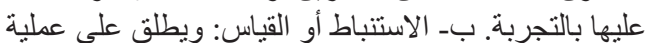

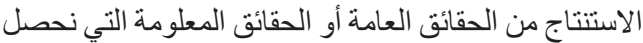

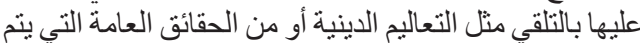
التوصل إليها باستقر اء الحقائق الجزئية.

ويمكن الحصول علي المعرفة من نوعين من المصادرذكر ها

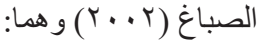

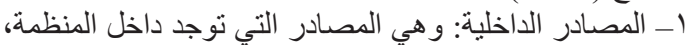

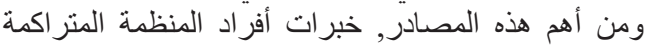

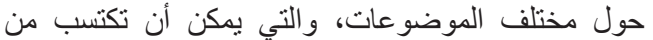

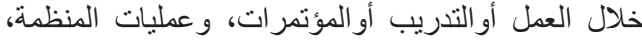
و المكتبات الداخلية، و البحوث و التخول المختر عات الداخلية.

r- المصادر الخارجية: و وهي المصادر التي توجد خارج المنظمة، والتي تظهر في البيئة المحيطة بها، ويتو الفر التر لديها

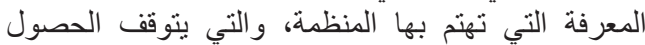

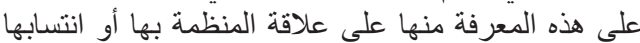

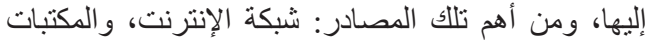

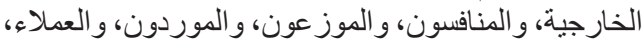

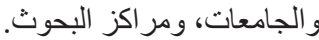

وأجمعت الدراسات السابقة التي تم إجراؤها في مجال

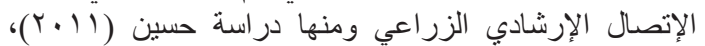

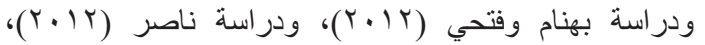

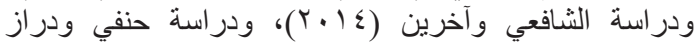

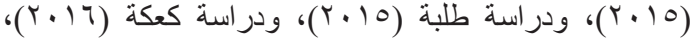

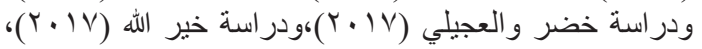

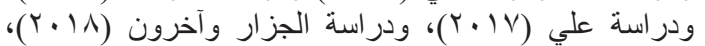

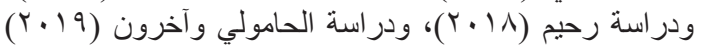
علي أهمية عملية الإتصال الإرشادي بين العاملين الإرشاديين

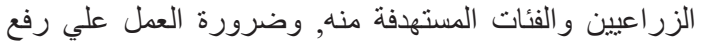

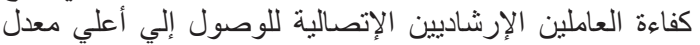

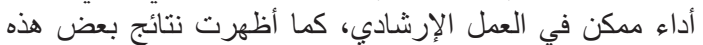

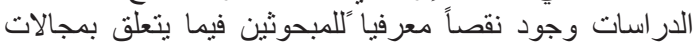
عمل الإرشاد الزراعي والأنشطة الإتصالية المؤداه مع الفئات فئات

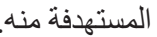
الأسلوب البحثى

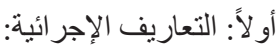

1- معارف العاملين الإرشاديين بالأنشطة الإتصالية: ويقصد بها درجة معارف المبحوثين بالأنشطة الإتصالية الإرشادية الإنهاية

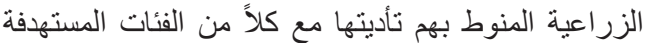

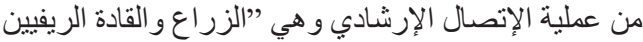

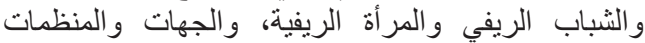

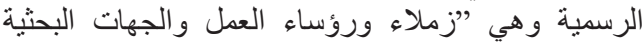

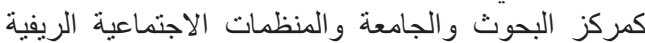

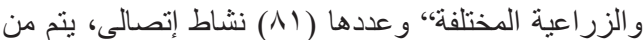

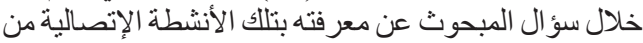

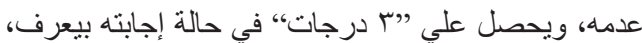

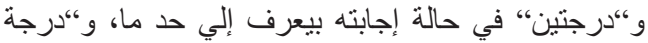

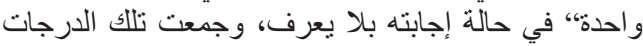

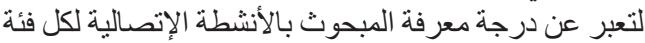
من الفئات المستهدفة.

r- سـن المبحوث: ويقصد به عمر المبحوث حتى وقت تجميع

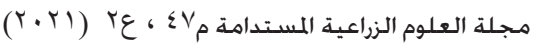

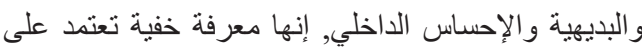

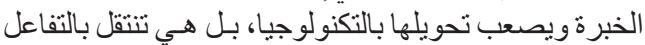
الاجتماعي.

وحدد صيني ( ب99 1 ) أربعة مصادر للمعرفة المكتسبة وهي:

1ـ التلقي: من وسائل اكتساب المعرفة ومن مصادر ها المهمة

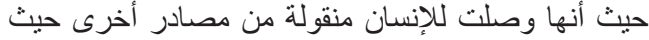

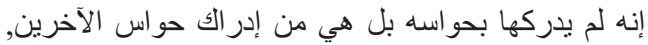

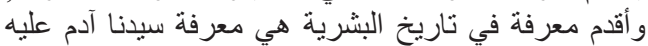

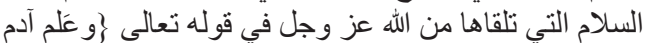
الأسماء كلها ثم عرضهم على الملائكة فقال أنبئوني بأسماء

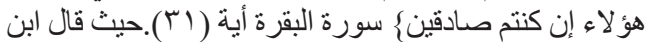

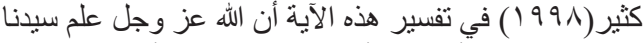

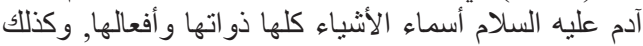

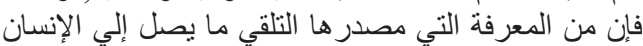
عبر المطبو عات و الإذاعات أو شبكات التلفاز

r- الملاحظـة: تعتبر الملاحظة من مصادر المعرفة التلقائية

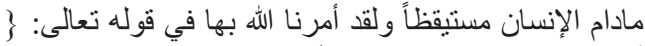

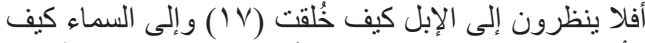

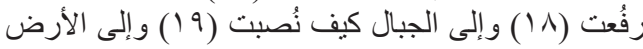

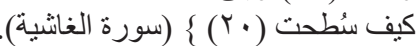

ويفسر ابن كثير الآية حيث يقول رب العالمين تعالى آمراً

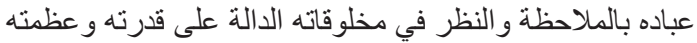

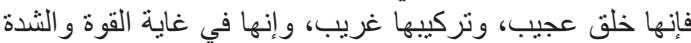

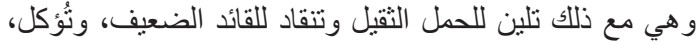

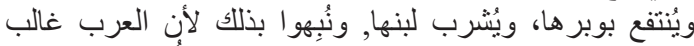

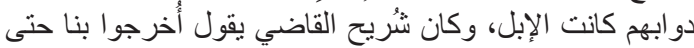

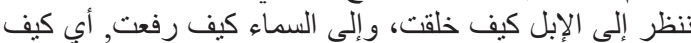

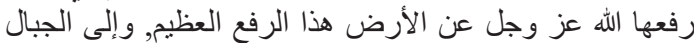

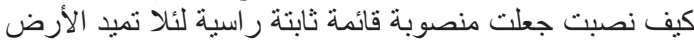

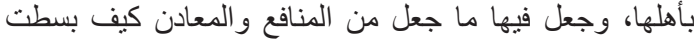

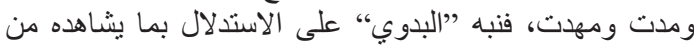

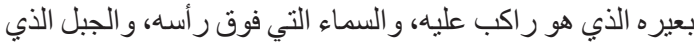

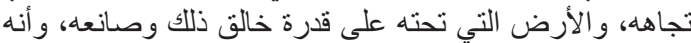

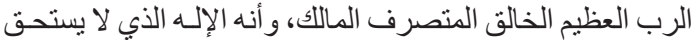

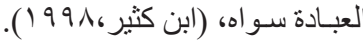

r- التجربـة: فالتجربة تعتبر عملية ملاحظة لظاهرة أسهر

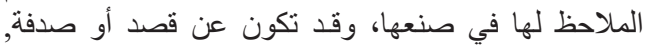

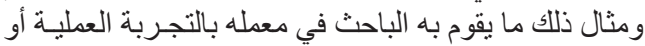
يخطط لها ويشترك في تنفيذها ليقوم بعملية ملاحظة لبن لنتائج

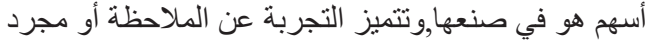

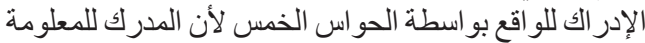

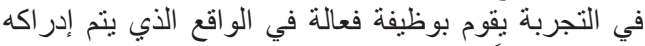

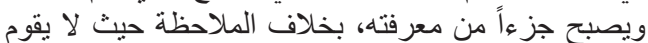

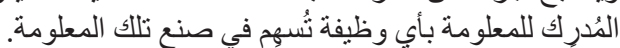

ع- الاستنتاج: ويكون بوجهين وهما: أـ الاستقراء: عملية

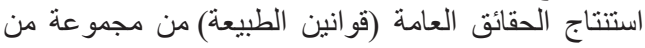

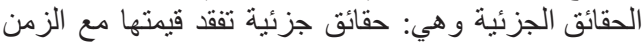

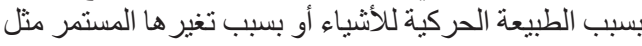

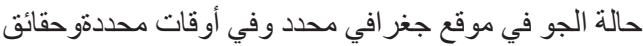

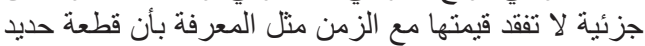
محددة أكثر ثقلاً من قطعة خشب في حجمهاو الحقائق الجزئية فئية 


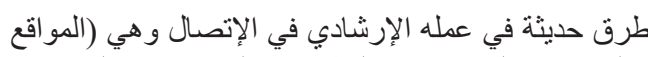

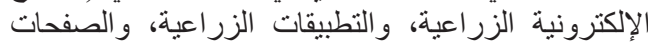

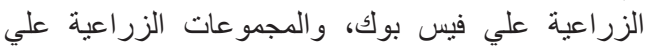

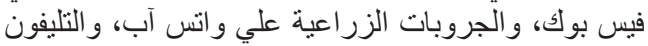

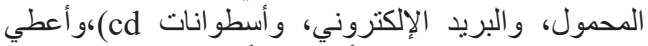

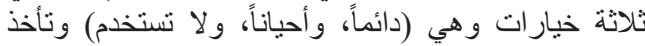

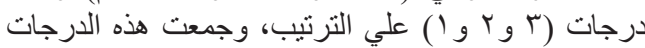

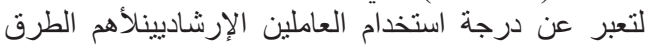
الإتصالية الإرشادية الحديثة.

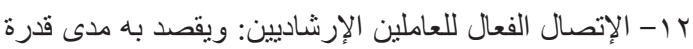

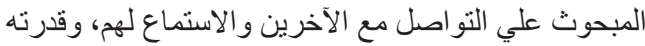

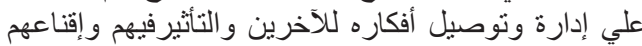

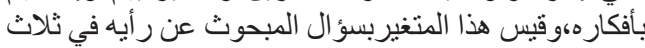

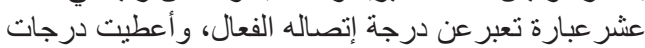

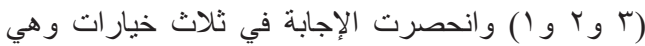

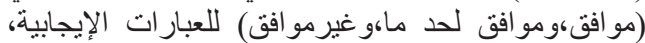

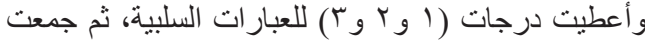

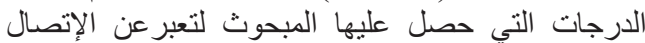
الفعال للعاملين الإرشاديين.

ثانباً: متغير ات البحث: اث:

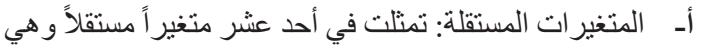

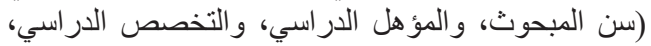

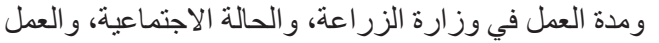

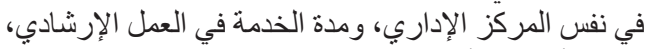

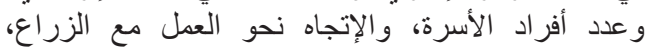

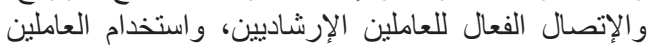
الإرشاديين للطرق الإتصالية الإرشادية الحديثة.

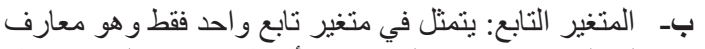

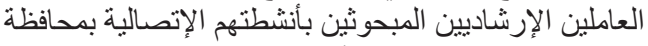

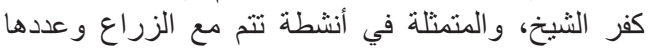

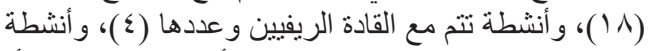

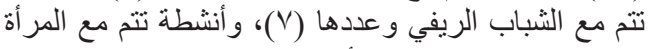

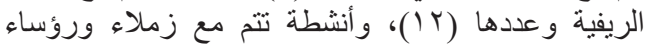

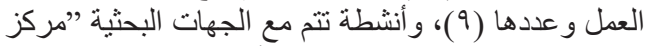

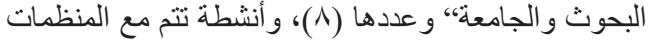

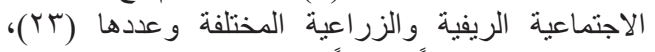

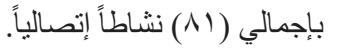

ثالثاً: منطقة وشاملة البحث:

أجري البحث على إنى جميع العاملين الإرشاديين بالجهاز

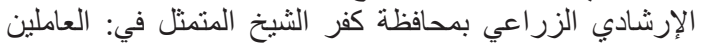

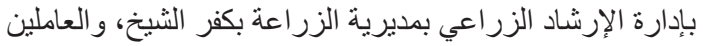

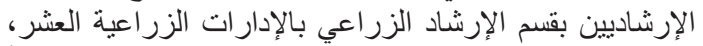

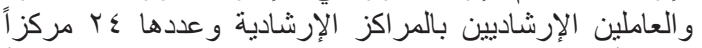

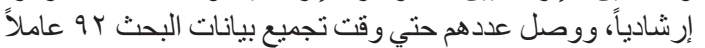

إرشنادياً.

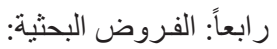
الفرض البحثي الأول: يتوقع وجود علاقة ارتباطية معنوية

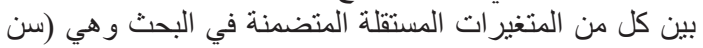

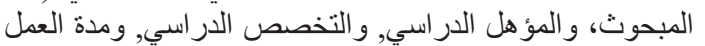

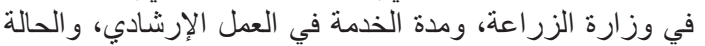

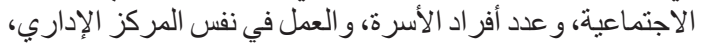

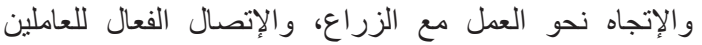

بيانات هذاالبحث, وقيس هذا المتغير بسؤال المبحوث عن

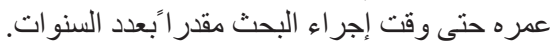

r- المؤهل الدراسي: ويقصد به نوع المؤهل الدراسي الحاصل

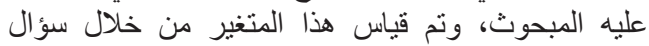

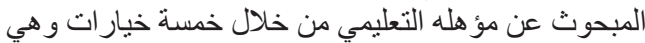

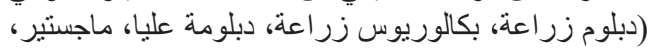

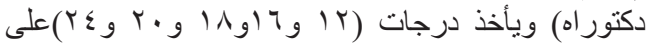
الترتيب.

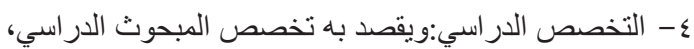

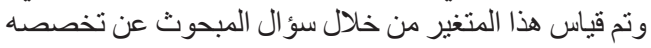

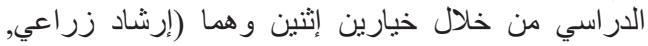

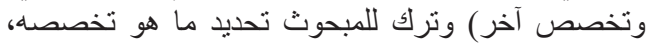

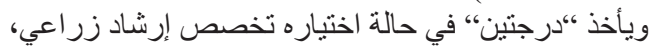

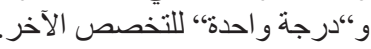

0- مدة العمل في وزارة الزر اعة: ويقصد به مدة عمل المبحوث

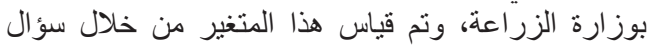

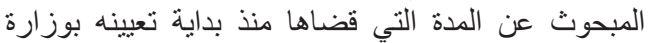

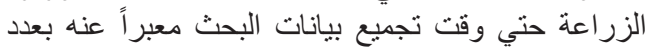
السنوات.

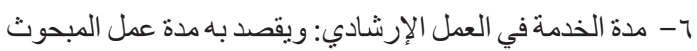

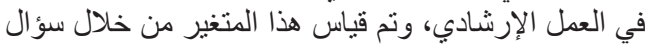

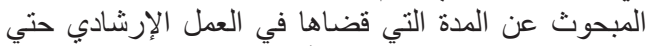

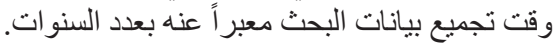

- الحالة الاجتماعية: ويقصد بها الحالة الاجتماعية للمبحوث

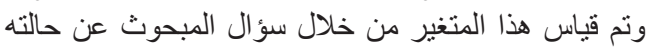

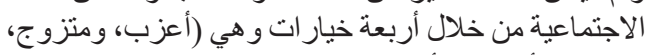

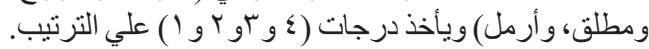

^- عدد أفراد الأسرة: ويقصد به عدد أفر اد أسرة المبحوث حتي

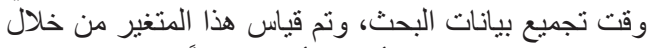

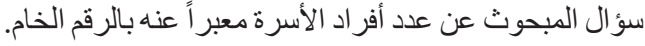

9- العمل في نفس المركز الإداري: ويقصد به عمل المبحوث في نفس المركز الإداري الذي يقيم فيه حتي وقت تجني تجميع بيانات

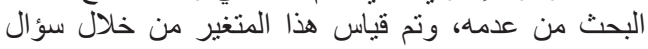

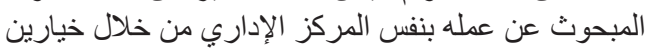
إثنين (نعم و لا) ويأخذ (r و ا ) درجة علي الإدي الترنيب.

• ا- الإتجاه نحو العمل مع الزراع: ويقصد به درجة ميل

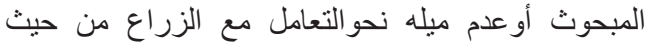

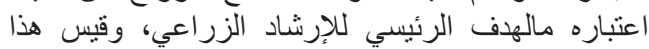

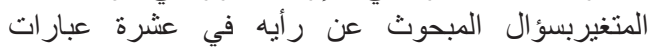

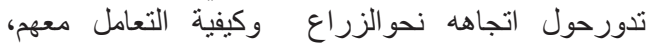

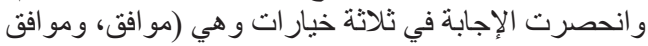

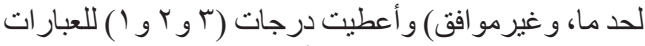

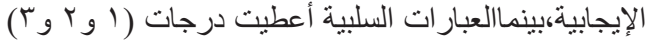

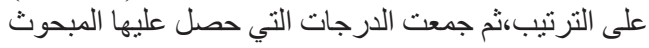
لتعبر عن اتجاهل نحو العمل مع الزر التراع.

11-استخدام العاملين الإرشاديين لأهم الطرق الإتصالية

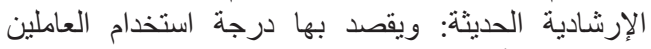

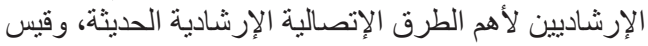

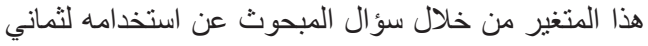

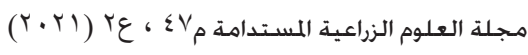




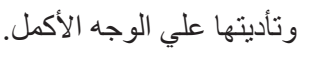

وفيما ينعلق بمدة العمل في وزارة الزر اعة فقد كثفت النتائج

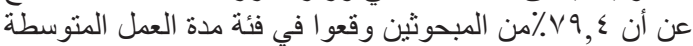

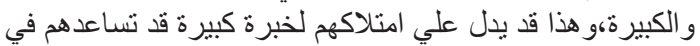
القيام بالأنشطة الإتصالية الكنوطة بهم و تأديتها علي الوجه الأكمل.

بينما مدة الخدمة في العمل الإرشادي فقد أظهرت النتائج

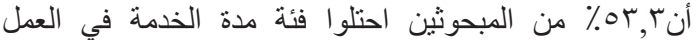
الإرشادي المتوسطة و الكبيرة، وقد يدل هذا لإندا علي امتلاكهم لخبرة جيدة في مجال الإتصال الإرشادي.

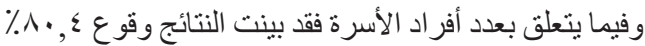

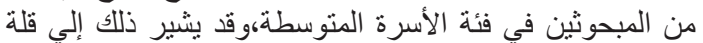

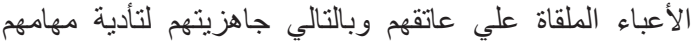
الإتصالية الإرشادية بكفاءة.

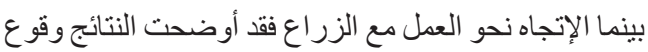

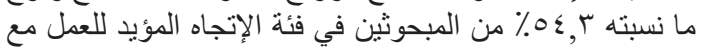

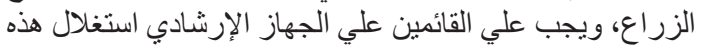
النقطة الإيجابية بما يساهم في تقايم خدمة إرشادية جيدة للزراع. الإن.

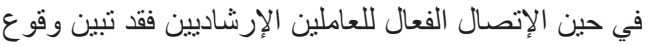

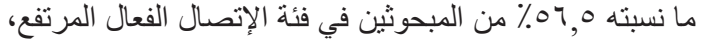

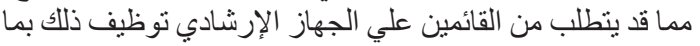
يحقق أهدافه الإتصالية ويخدم العمل الإرشادي.

بينما استخدام العاملين الإرشاديين للطرق الإتصالية الإرشادية الإناية

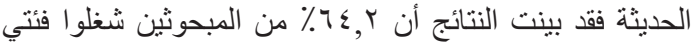

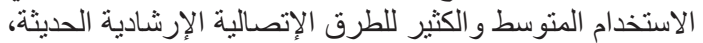
و هذا قد يعد مؤشر أ إيجابياً نحو العمل علي تطوير العمل الإرشادي العادي و الانتقال من القديم للحديث.

وفيما يتعلق بالعمل في نفس المركز الإداري فقد أظهرت

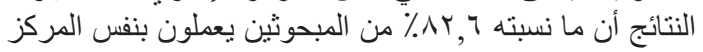

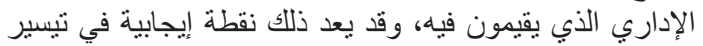

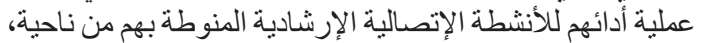
و الحفاظ على وقتهم ومجهو داتهم واستغلالها في العمل الإرشادي نالئي

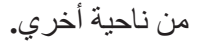

ثانياً: معارف العاملين الإرشاديين المبحوثين بالأنشطة الإتصالية و الإرشادية:

أــ درجة معارف العاملين الإرشاديين المبحوثين بالأنشطة الإتصالية مع الفئات المستهدفة من عملية الإتصال الإرشادي:

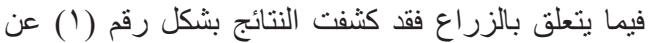

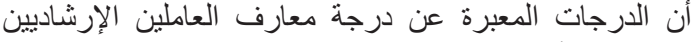

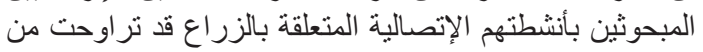

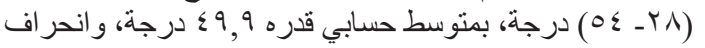

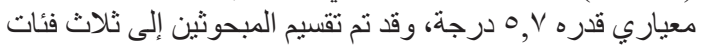

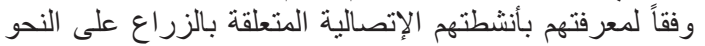

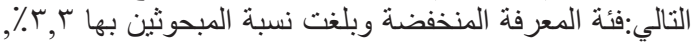

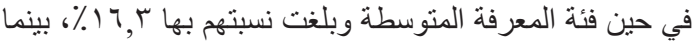

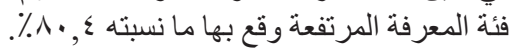

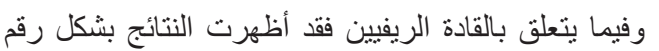

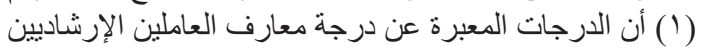

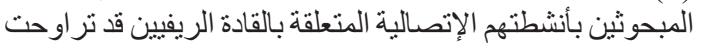

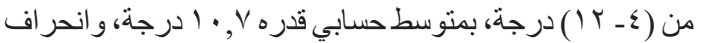

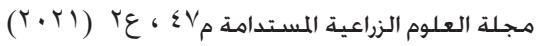

الإرشاديين، واستخدام العاملين الإرشاديين للطرق الإتصالية

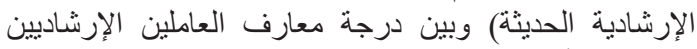
المبحوثين بأنشطتهم الإتصالية كمتغير تابع.

الفرض البحثي الثاني: يتوقع أن ترتبط المتغيرات المستقلة

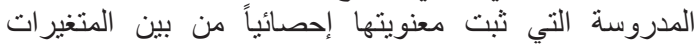
المتضمنة بالبحث مجتمعة بدرجة معارف العاملين الإرشاديين المبحوثين بأنشطتهم الإتصالية كمتغير تابع.

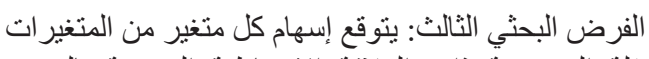

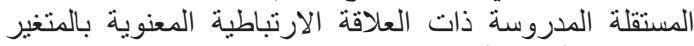

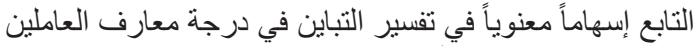
الإرشاديين المبحوثين بأنثطتهم الإتصالية كمتغير تابع.

خامساً: جمع وتحليل البيانات البحثية: جمعت بيانات هذا البحث من جميع المبحوثين بواسطة

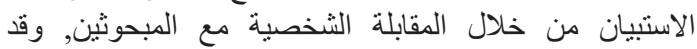

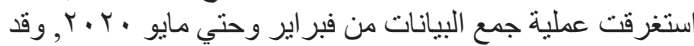

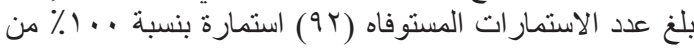
عينة البحث. علئ.

وبعدجمع البيانات ومراجعة استمارات الاستبيان التي تم جمعها ميدانياً ومكتبياً من أجل التأكد من استيفاء جميع البيات التيانات

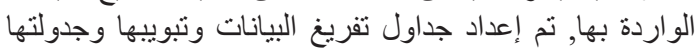
وتصنيفها وفقا لمتطلبات البحث, وتم إدخال وتحات وتحليل البيانات باستخدام البرنامج الإحصائي

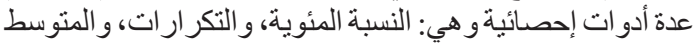

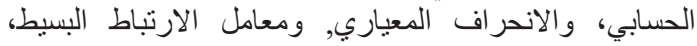

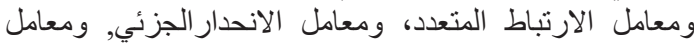

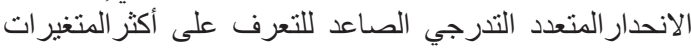
المستقلة ذات التأثير المعنوي التي تسهم في تفسير التباين في التئري

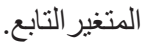

النتائج البحثبة

أو لاً: بعض الخصائص المميزة للعاملين الإرشاديين المبحوثين:

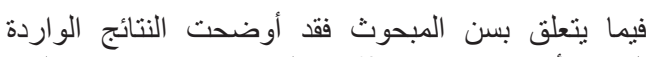

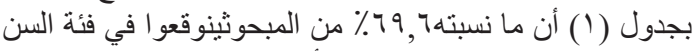

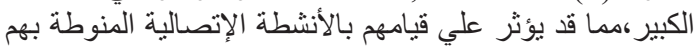

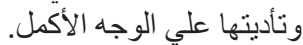

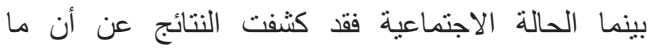

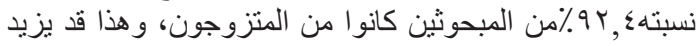
من الأعباء الملقاة علي عاتقهم وقد يؤثر علي قار التهم الإتصالية

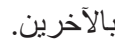

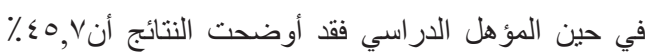

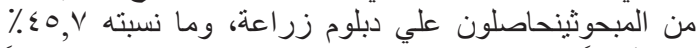

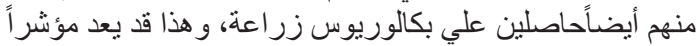

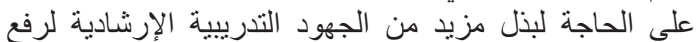
كفاءة المبحوثين الحاصلين علي دبلوم زر اعة في مجال الإتصال للال

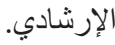

أما فيما يتعلق بالتخصص الدراسي للمبحوثين فقد بينت النتائج

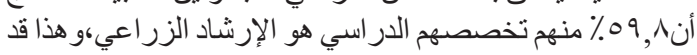

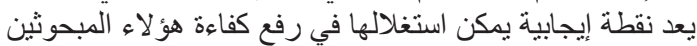

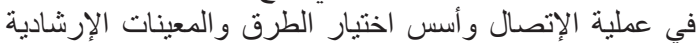
... إلخ، حتي يتسنى لهم القيام بالأنثطة الإتصالية المنوطة بهر الأنشادية 
المبحوثين بها ^, • ( ٪, في حين فئة المعرفة المتوسطة فقد بلغت

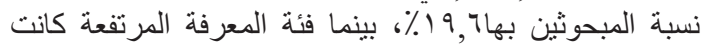
نسبتهم بها قدر ها 79,79

وفيما يتعلق بالمر أة الريفية فقد أظهرت النتائج بشكل رقم

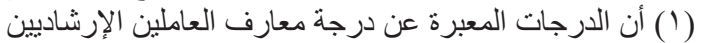

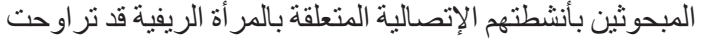

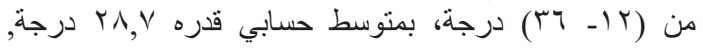

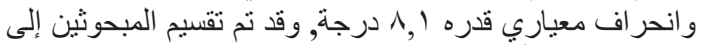

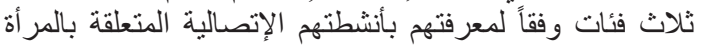

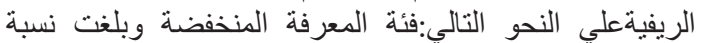

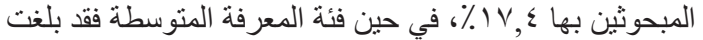

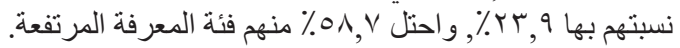

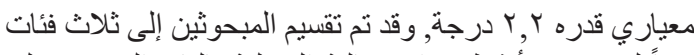

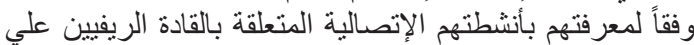

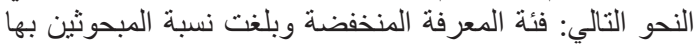
؟, ٪\%, أما فئة المعرفة المتوسطة فقد بلغت نسبة المبحوثين بها

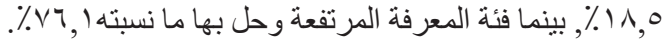

وفيما يتعلق بالثباب الريفي فقد بينت النتائج بشكل رقم (1)

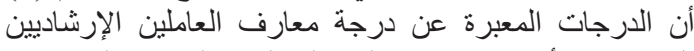

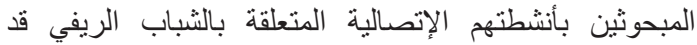

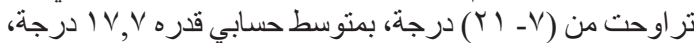

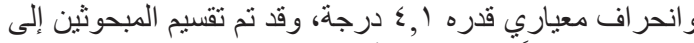
ثلاث فئات وفقاً لمعرفتهم للأنشطة الإتصالية المتعلقة بالثباب الريفيعلي النحو التالي: فئة المعرفة المنخفضة ولئلة وبلغت نسبة

\begin{tabular}{|c|c|c|c|c|c|}
\hline \multicolumn{6}{|c|}{ جدول 1. توزيع العاملين الإرشاديين المبحوثين وفقاً لبعض الغصائص المميزة لهم } \\
\hline$\%$ & عدد & الخصائص & $\%$ & علدد & الخصائص \\
\hline \multicolumn{3}{|c|}{ مدة العمل في وزارة الزراعة } & \multicolumn{3}{|r|}{ 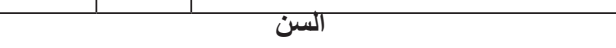 } \\
\hline$T \cdot, Y$ & 19 & صغيرة (0 إلي 10 () سنة & $9, \wedge$ & 9 & صغير ( Y إلي VY) سنة \\
\hline$\varepsilon \leqslant, 7$ & §1 & متوسطة (7 17 إلي 4 (Yنة & $r \cdot, r$ & 19 & متوسط (^ץ إلي ^^) سنة \\
\hline$r \leqslant, \wedge$ & Tr & كبيرة (YV إلي YV سنة & 79,7 & $T \varepsilon$ & كبير (9 (إلي 990) سنة \\
\hline \multicolumn{2}{|c|}{ ع } & ألمنو سط الحسابي & \multicolumn{2}{|c|}{ 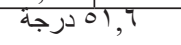 } & الأتضوسط الحسابي \\
\hline \multicolumn{2}{|c|}{ 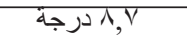 } & الانحراف المعياري & \multicolumn{2}{|c|}{ ل V, Vرجة } & الانحر اف المعياري \\
\hline \multicolumn{3}{|c|}{ عدد أقراد الأسرة } & \multicolumn{3}{|c|}{ مدة الخَمة في العمل الإرشتشادي } \\
\hline $17, r$ & 10 & صغيرة (ا إلي ب) أفر اد & $\varepsilon 7, \vee$ & $\varepsilon r$ & صغيرة (1 إلي (') سنة \\
\hline$\Lambda \cdot, \varepsilon$ & $V \varepsilon$ & متوسطة (ع إلي 7) أفراد & $r T, V$ & r & منوسطة (Y إلي Y Y) سنة \\
\hline$r, r$ & $r$ & كبيرة (V إلي q) أفر اد & 19,7 & 11 & كبيرة (Tr إلي سٓ سنة \\
\hline \multicolumn{2}{|c|}{ V } & المنتوسط الحسابي & \multicolumn{2}{|c|}{ |, } & 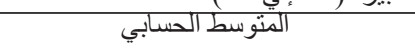 \\
\hline \multicolumn{2}{|c|}{ T, ادرجة } & الانحر اف المعياري & \multicolumn{2}{|c|}{ لري درجة } & الانحر اف المعياري \\
\hline \multicolumn{3}{|c|}{ الإتجاه نحو العمل مع الزراع } & \multicolumn{3}{|c|}{ العمل في نفس المركز الإداري } \\
\hline $0, \xi$ & 0 & معارض (• إلي זب) درجة & Nr,, 1 & V7 & يعمل \\
\hline$\varepsilon \cdot, \Gamma$ & TV & محايد (Y إلي VT) درجة & $T V, \varepsilon$ & 17 & لا يعمل \\
\hline $0 \leqslant, \Gamma$ & 0. & مؤيد (ما إلي • ب) درجة & \multicolumn{2}{|c|}{ 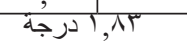 } & المتوسط الحسابي \\
\hline \multicolumn{2}{|c|}{ (0,7 درجة } & المتوسط الحسابي & \multicolumn{2}{|c|}{ | } & الانحراف المعياري \\
\hline \multicolumn{2}{|c|}{ 'ו" } & الانحراف المعياري & \multicolumn{3}{|r|}{ التخصص الاراسني } \\
\hline \multicolumn{3}{|c|}{ الإتصال الفعال للعاملين الإرشتساديين } & 09,1 & 00 & إرشاد زر اعي \\
\hline$T$, & $\pi$ & منخفض (" ז إلي • ") درجة & $\varepsilon \cdot, r$ & rV & تخصص آخر \\
\hline T, 0 & pq & منوسط (ا إلي مب) درجة & \multicolumn{2}{|c|}{ 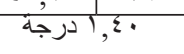 } & المتوسط الحسابي \\
\hline 09,0 & or & 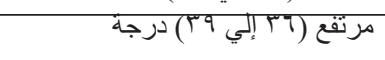 & \multicolumn{2}{|c|}{ |9 } & الانحراف المعياري \\
\hline \multicolumn{2}{|c|}{ " } & المتوسط الحسابي & \multicolumn{3}{|r|}{ الحالة الاجتماعية } \\
\hline \multicolumn{2}{|c|}{ 2, آدرجة } & الانحر اف المعياري & 1,1 & 1 & أعزب \\
\hline & مادية & استخذام العاملين الإرشّاديين & $94, \varepsilon$ & 10 & متزوج \\
\hline ro,, 1 & TT & منخفض (A إلي سا") درجة & $\cdot$ & صفر & مطلق \\
\hline or, & ₹9 & متوسط (ع إلبي 9 1) درجة & 7,0 & 7 & 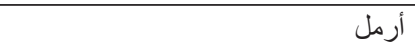 \\
\hline $1 \cdot, 9$ & T. & كتير (• إلي ع آ) درجة & & & الهنوسط الحسابي \\
\hline |جرة & & المتوسط الحسابي & & & الانحراف المعياري \\
\hline & & الانحراف المعياري & & & المؤهل الاراسي \\
\hline & & & $\varepsilon 0, V$ & $\varepsilon T$ & دبلوم زر اعة \\
\hline & & & $\varepsilon 0, V$ & हा & بكالوريوس زر اعة \\
\hline & & & $\because \cdot$ & صفر & دبلومة عليا \\
\hline & & & 7,0 & 9 & ماجستير \\
\hline & & & T, & T & دكتوراه \\
\hline & & & |" & & المتوسط الحسابي \\
\hline & & & رجة & & الانحر اف المعياري \\
\hline & & & & & المصدر: حسبت من استمارات الاستبيان \\
\hline
\end{tabular}




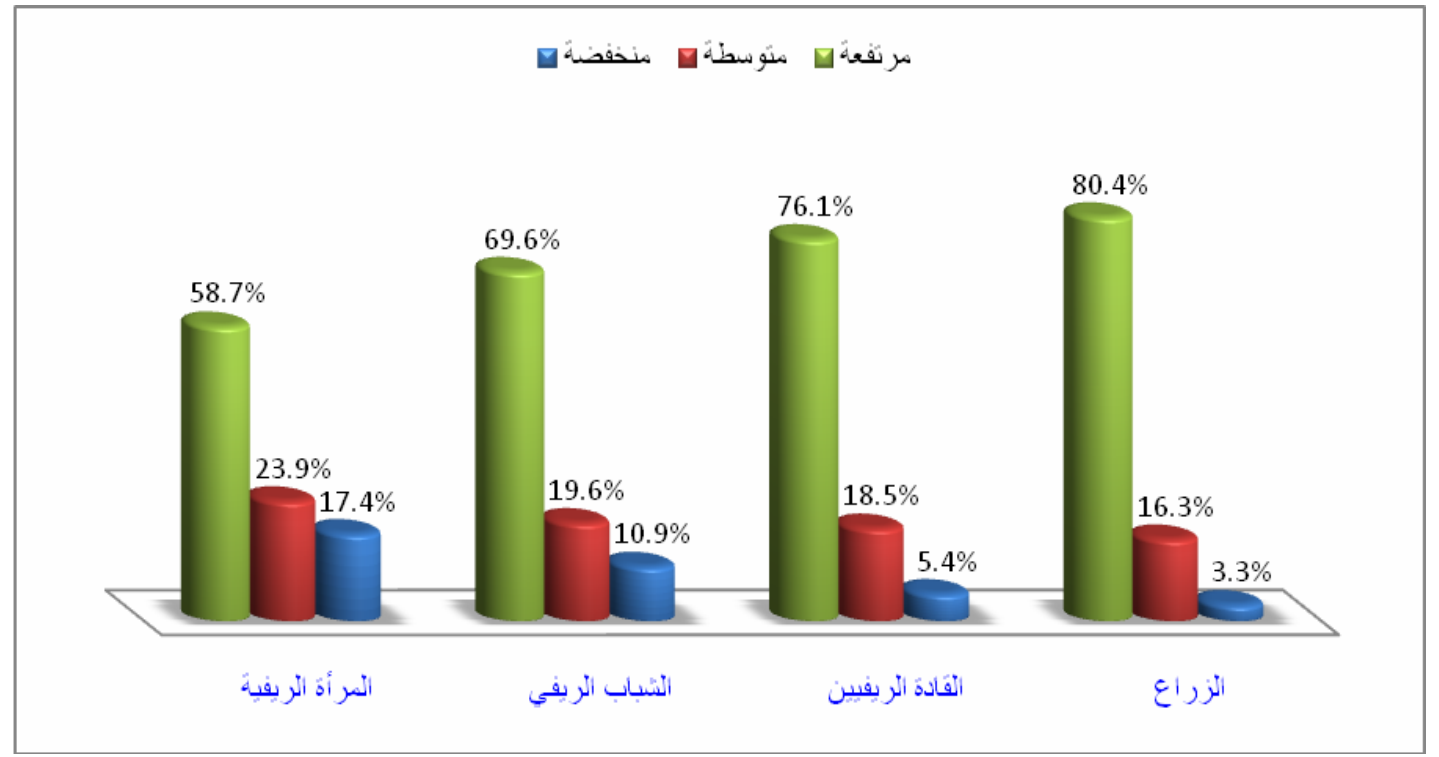

شكل 1. توزيع العاملين الإرشاديين المبحوثين وفقاً لارجة معرفتهمبالأنشطة الإتصالية للفئات المستهذفة

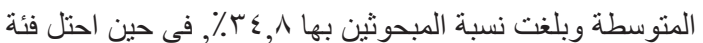
المعرفة المرتفعة .0 \% منهم.

وللتعرف علي أكثر الأنشطة الإتصالية للعاملين الإرشاديين

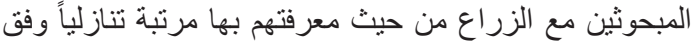

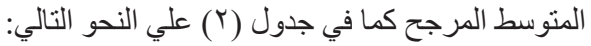

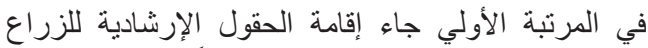

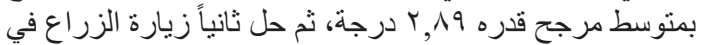

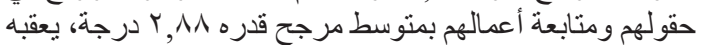

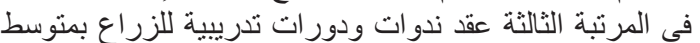

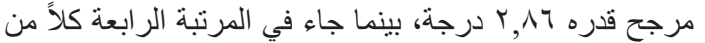

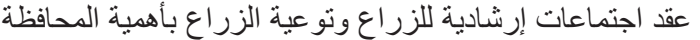

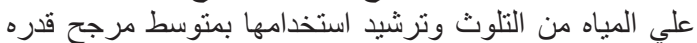

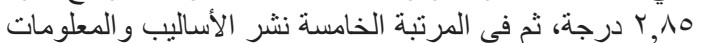

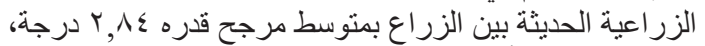

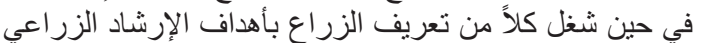

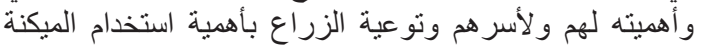

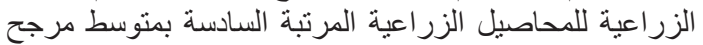

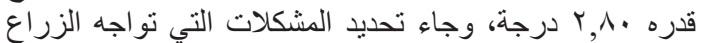

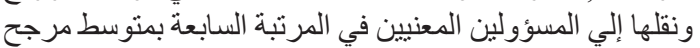

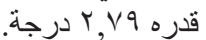

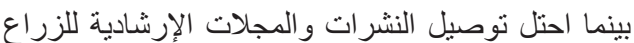

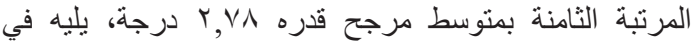

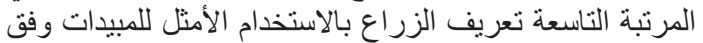

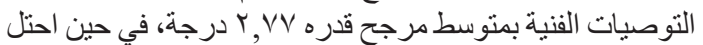

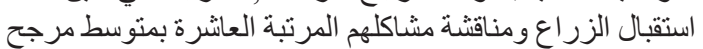

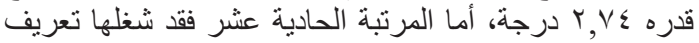
الزراع بأهمية الحفاظ علي البيئة و الموارد الطبة الطبيعية من التلوثر

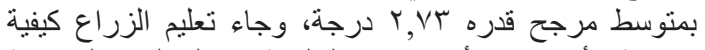

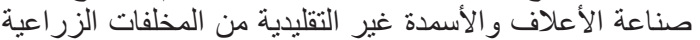

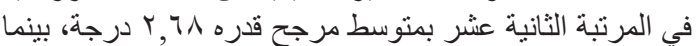
شغل تحديد معوقات تنفيذ الزراعة للتونية مبرديات العلمية المرتبة الثالثة

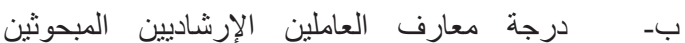
للأنشطة الإتصالية مع الجهات و المنظمات الرفين الرسمية:

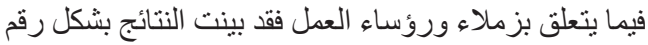

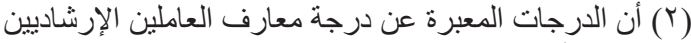

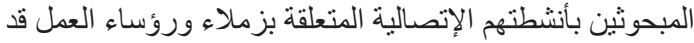

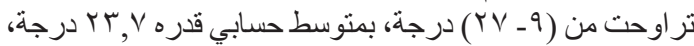

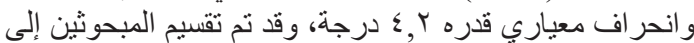

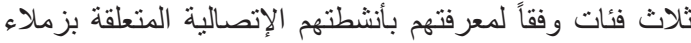

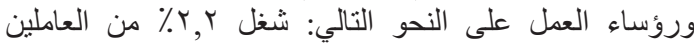
الإرشاديين المبحوثين فئة المعرفة المنخفضة في حين فئة المعرفة

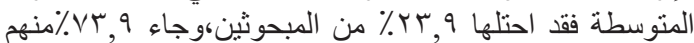

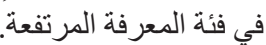

أما الجهات البحثية (مركز البحوث، والجامعة) فقد كثفت

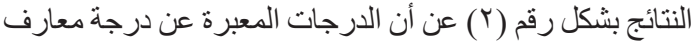

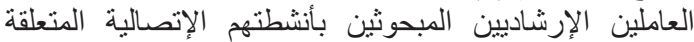

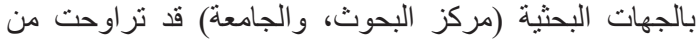

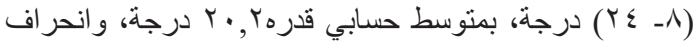

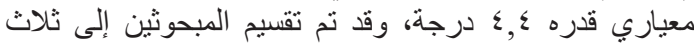

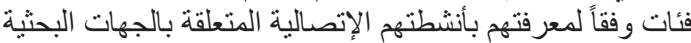

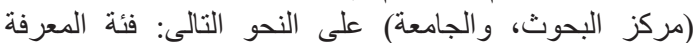

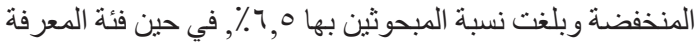

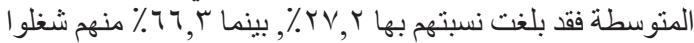

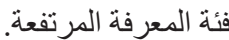

في حين المنظمات الاجتماعية الريفية والزراعية المختلفة

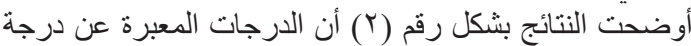

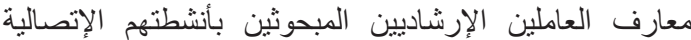

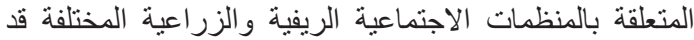

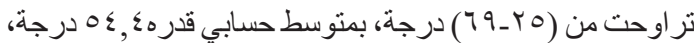

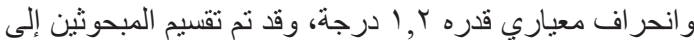

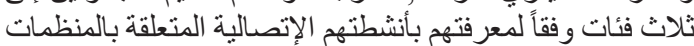

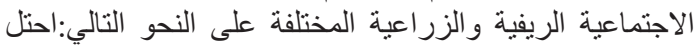

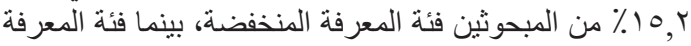


إمداد الزر اع بالمعلومات و الأنباء التسويقية وكيفية الاستفادة منها

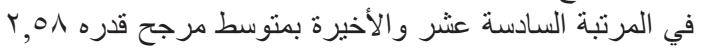
درجة (جدول بالمة).

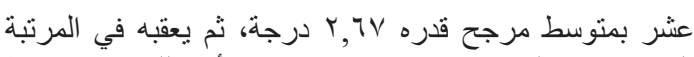

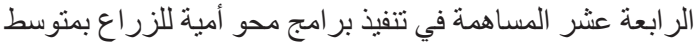

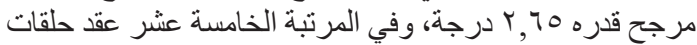

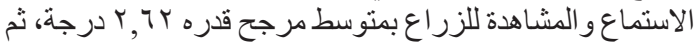

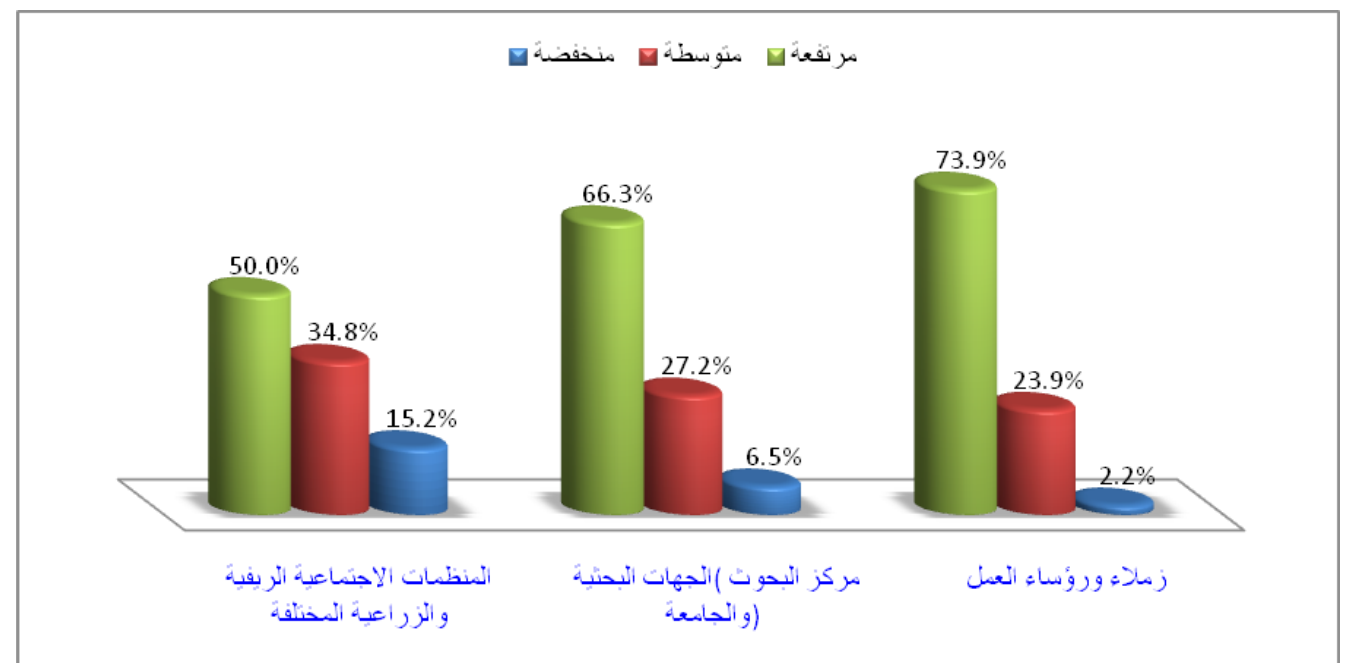

شكل r ـ توزيع العاملين الإرشاديين المبحوثين وفقاً لارجة معرفتهمبالأنشطة الإتصالية مع الجهات والمنظمات الرسمية

جدول r. توزيع العاملين الإرشاديين المبحوثين وفق معرفتهم بالأنثطة الإتصالية المتعلقة بالزراع

\begin{tabular}{|c|c|c|c|c|c|c|c|c|c|}
\hline \multirow{2}{*}{ الترتيب } & \multirow{2}{*}{ المرجتج المتط } & \multicolumn{2}{|c|}{ لا يعرف } & \multicolumn{2}{|c|}{ إلي حد ما } & \multicolumn{2}{|r|}{ يعرف } & \multirow{2}{*}{ الأنشطة الإتصالية } & \multirow[b]{2}{*}{ م } \\
\hline & & $\%$ & 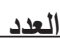 & $\%$ & العَّد & $\%$ & العدد & & \\
\hline 7 & $\uparrow, \wedge$. & $r, r$ & r & $17, r$ & 10 & $\wedge 1,0$ & vo & تعريف الزراع بأهداف الإرشاد الزراعي وأهميته & 1 \\
\hline 1. & $r, V \varepsilon$ & 1,1 & 1 & $V, 7$ & $\mathrm{v}$ & $91, r$ & $\Lambda \varepsilon$ & استقال الزراع ومناقشة مشاكلهـ & $r$ \\
\hline r & $r, \wedge \wedge$ & 1,1 & 1 & 9,1 & 9 & $\wedge 9,1$ & Ar & زيارة الزراع في حقولهح ومتابعة أعمالهي & r \\
\hline 1 & $r, \wedge 9$ & $r, r$ & r & 7,0 & 7 & $91, r$ & $\Lambda \varepsilon$ & إقامة الحقول "الزرشادية للزراء & $\varepsilon$ \\
\hline r & $r, \Lambda T$ & $r, r$ & r & $\Lambda, \vee$ & $\Lambda$ & $\wedge 9,1$ & Ar & عقد ندوات ودورات تدربيية للزراع & 0 \\
\hline$\varepsilon$ & $r, \wedge 0$ & $r, r$ & r & $\vee, 7$ & $\checkmark$ & $\wedge 9,1$ & Ar & عقد اجتماعات إرشادية للزراع & 7 \\
\hline$\Lambda$ & Y.VA & $r, r$ & r & $1 V, \varepsilon$ & 17 & $\Lambda \cdot, \varepsilon$ & $V \varepsilon$ & توصيل النشرات والمجلات الإرشادية للزراع & $\mathrm{V}$ \\
\hline 7 & $\uparrow, \wedge$. & $\varepsilon, r$ & $\varepsilon$ & $1 \cdot, 9$ & $1 \cdot$ & $\wedge \varepsilon, \wedge$ & $\vee \wedge$ & تلمحاصية الزراع بأهمية استخدام الميكنة الزراعية & $\wedge$ \\
\hline 11 & $r, V T$ & $V, T$ & v & Ir, & 11 & $\Lambda \cdot, \varepsilon$ & $V \varepsilon$ & تعريف الزراع بأهمية الحفاظ علي البيئة & 9 \\
\hline 10 & $r, 7 r$ & $i_{1}$. & 11 & $1 \leqslant, 1$ & ז & $v r, q$ & $7 \Lambda$ & عقد حلقات الاستماع والمشاهدة للزراع & 1. \\
\hline$\varepsilon$ & r, ^o & r & r & $\vee, 7$ & $\mathrm{v}$ & $\wedge 9,1$ & Ar & تلتوعية الزراعِ بأهمية المحافظة علي المياه من & 11 \\
\hline Ir & 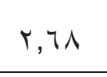 & $1 \cdot, 9$ & 1. & $1 \cdot, 9$ & 1 . & $\vee \wedge, r$ & VT & تعليم الزتلراع كيفية صناعة المخلفات الزعاعلاف والأسمدة & it \\
\hline 9 & r,,$V$ & $0, \varepsilon$ & o & Ir,. & 11 & $\wedge r, r$ & $\vee 7$ & تعريف الزراع بالاستخدام الأمثل للمبيدات وفق & 几 \\
\hline $\mathrm{V}$ & $r, \vee q$ & $\varepsilon, r$ & $\varepsilon$ & Ir, & 11 & $\Lambda \Gamma, v$ & VV & تحديد المشكلات التي تواجه الزراع ونقلها إلي & $1 \leqslant$ \\
\hline Ir & $r, 7 \mathrm{~V}$ & $\varepsilon, r$ & $\varepsilon$ & $r r, q$ & rt & $\vee 1, \Lambda$ & 77 & تحديد معوقات تنفيذ الزراع للتوصيات العلمية & 10 \\
\hline 17 & $r, 0 \wedge$ & Ir, & 11 & $1 \wedge, \varepsilon$ & IV & 79,7 & $7 \leq$ & 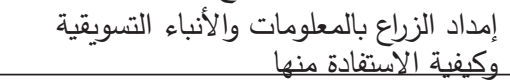 & 17 \\
\hline ० & $\curlyvee, \wedge \varepsilon$ & $r, r$ & r & $9, \wedge$ & 9 & $\wedge \uparrow, q$ & $\wedge$. & نشر الأساليب والمعلومات الزراعية الحديثة & iv \\
\hline $1 \varepsilon$ & $r, 70$ & $V, 7$ & $\checkmark$ & 19,7 & 11 & $\vee r, \wedge$ & iv & المساهمة في تتفيذ برامج محو أمية للزراع & 11 \\
\hline
\end{tabular}

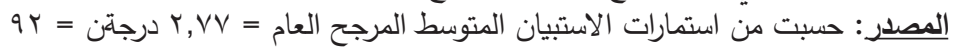


بينما احتل تعريف الثباب الريفي بأهمية دوره في تتمية

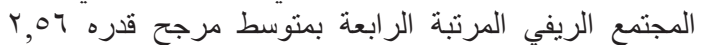

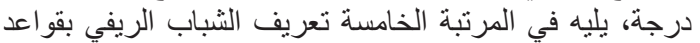

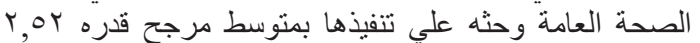

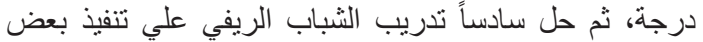

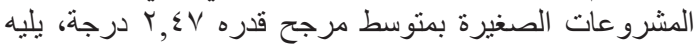

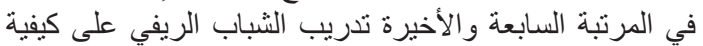

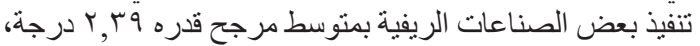

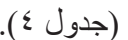

ولللتعرف علي أكثر الأنثطة الإتصالية للعاملين الإرشاديين

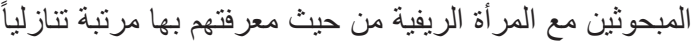

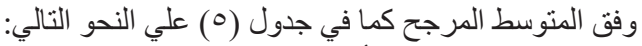

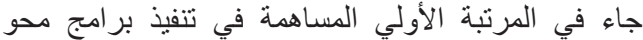

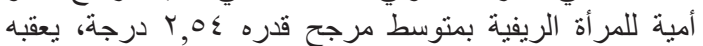
في المرتبة الثانية تعريف المرأة الريفية بالأساليب الصحيحة درئية

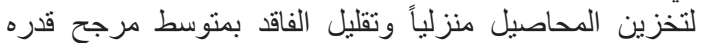

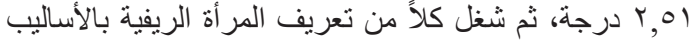

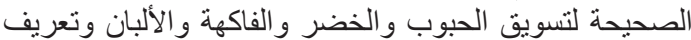

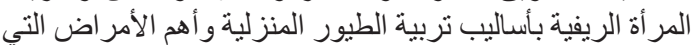
تصييها المرتبة الثالثة بمتوسط مرجح قدره ـ. ب ب درجة.
وللتعرف على أكثر الأنشطة الإتصالية للعاملين الإرشاديين

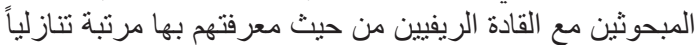

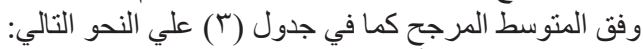

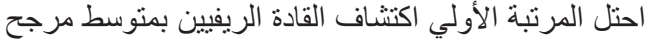

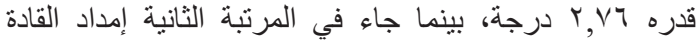

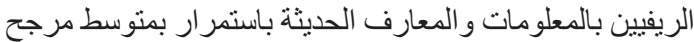

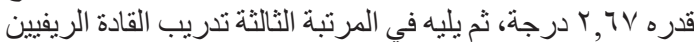

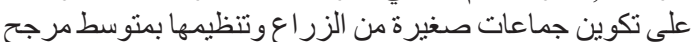

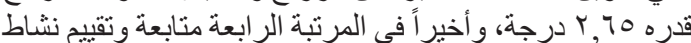

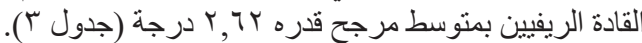
وللتعرف علي أكثر الأنشطة الإتصالية للعاملين الإرشاديين

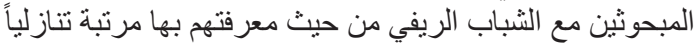

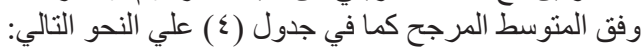
جاء تثجيع الثباب الريفي علي الاشتراك الك في الأنشطة

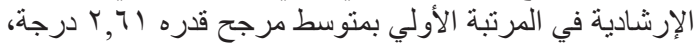

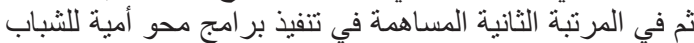

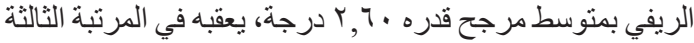

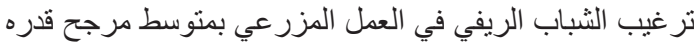

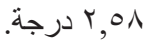

جدول ऍ. توزيع المبحوثين وفق معرفتهم بالأنشطة الإتصالية المتعلقة بالقادة الريفيين

\begin{tabular}{|c|c|c|c|c|c|c|c|c|c|}
\hline \multirow{2}{*}{ الترتيب } & \multirow{2}{*}{ المرجح } & \multicolumn{2}{|c|}{ ل لا يعرف } & \multicolumn{2}{|c|}{ إلي حد ما } & \multicolumn{2}{|c|}{ يعرف } & \multirow{2}{*}{ الأنثطة الإتصالية } & \multirow{2}{*}{ p } \\
\hline & & $\%$ & 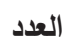 & $\%$ & العدد العد & $\%$ & العدد العد & & \\
\hline 1 & $Y, V T$ & 0,0 & 0 & $1 \%$ & ir & 11,0 & vo & اكتشاف القادة الرنغيين & 1 \\
\hline r & $r, 70$ & 7,0 & 7 & $r, \wedge$ & $r_{1}$ & $V \cdot, V$ & 70 & تدغيب القادة الريفين علي تكوين جماعات & $r$ \\
\hline$r$ & Y,TV & $\Lambda, \vee$ & $\wedge$ & $17, r$ & 10 & vo, & 79 & الحديثة باستمرار القادييين بالمعلومات والمعارف & $r$ \\
\hline$\varepsilon$ & r,T & $9, \wedge$ & 9 & 11,0 & iv & $\vee \backslash, V$ & 77 & متابعة وتقييم نشاط القادة الرنفين & $\varepsilon$ \\
\hline
\end{tabular}

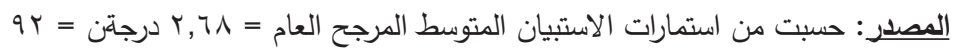

جدول ؛ ـ توزيع المبحوثين وفق معرفتهم بالأنشطة الإتصالية المتعلقة بالشباب الريفي

\begin{tabular}{|c|c|c|c|c|c|c|c|c|c|}
\hline \multirow{2}{*}{ الترتيب } & \multirow{2}{*}{ المتوسط } & \multicolumn{2}{|c|}{ لا يعرف } & \multicolumn{2}{|c|}{ إلي حد ما } & \multicolumn{2}{|c|}{ يعرف } & \multirow{2}{*}{ الأنشطة الإتصالية } & \multirow[b]{2}{*}{ م } \\
\hline & & $\%$ & العدد & $\%$ & العدد & $\%$ & العدد & & \\
\hline 7 & $T, \Sigma V$ & $10, r$ & $1 \varepsilon$ & $r, \Lambda$ & YI & $\pi r_{,}$ & or & 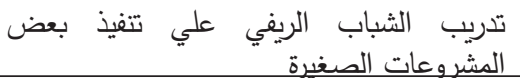 & 1 \\
\hline V & $r, r q$ & 19,7 & 11 & $r, \Lambda$ & YI & ov, T & or & تدريب الثباب الريفي على كيفية تتفيذ بعض & r \\
\hline 1 & $r, T)$ & $\wedge, \vee$ & $\wedge$ & YI,V & $r$. & 79,7 & $7 \varepsilon$ & تثنيع الثباب الريفي علي الاشتراك في & r \\
\hline$\varepsilon$ & r,07 & $1 \cdot, 9$ & 1. & $r, \Lambda$ & rI & r & 71 & تعريف الثباب الريفي بأهمية دوره في تتمية & $\varepsilon$ \\
\hline 0 & T,OY & IT,. & 11 & $r r, q$ & Tr & $7 \leqslant, 1$ & 09 & تعريف الثباب الريفي بقواعد الصحة العامة & 0 \\
\hline r & $r, 0 \Lambda$ & 9,1 & 9 & Y I, V & $r$. & $7 \Lambda, 0$ & אד & ترغيب الشّباب الريف & 7 \\
\hline r & $r, 7$. & $৭, \wedge$ & 9 & $r \cdot, \tau$ & 19 & 79,7 & $7 \varepsilon$ & المساهمة في تتفيذ برامج محو أمية للشباب & V \\
\hline
\end{tabular}

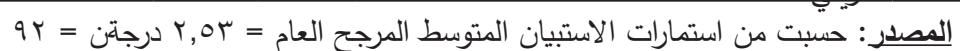

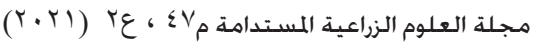




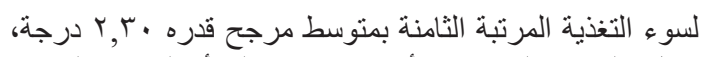

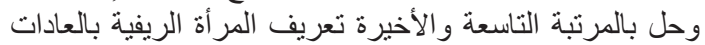

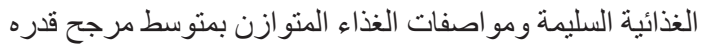

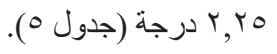

وللتعرف علي أكثر الأنشطة الإتصالية للعاملين الإرشاديين

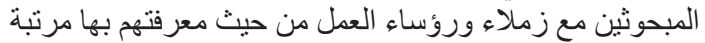
تنازلياً وفق المتوسط المرجح كما في جدول (7) علي النحو التالي:

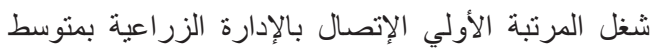

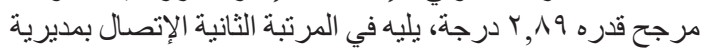

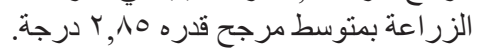

بينما احتل المرتبة الر ابعة عمل حملات تو عية للمر أة الريفية

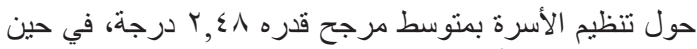

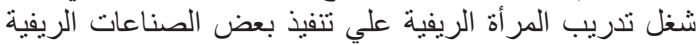

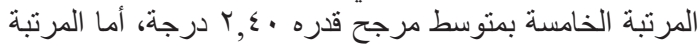

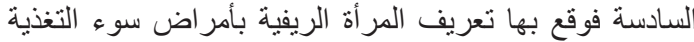

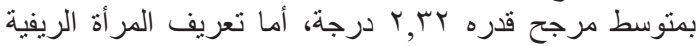

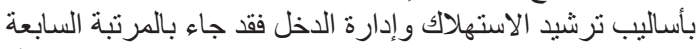

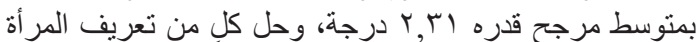

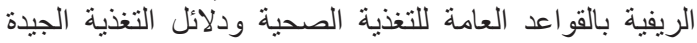

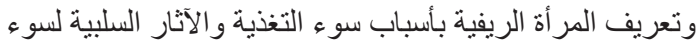
التغذية وتعريف المر أة الريفية بأسباب سوء التغذية والآثار السلبية

جدول ه. توزيع المبحوثين وفق معرفتهم بالأنثطة الإتصالية المتعلقة بالمرأة الريفية

\begin{tabular}{|c|c|c|c|c|c|c|c|c|c|}
\hline \multirow{2}{*}{ الترتيب } & \multirow{2}{*}{ المتوسط } & \multicolumn{2}{|c|}{ 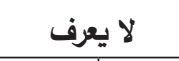 } & \multicolumn{2}{|c|}{ إلي حد ما } & \multicolumn{2}{|c|}{ 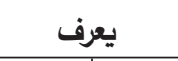 } & \multirow{2}{*}{ الأنشطة الإتصالية } & \multirow{2}{*}{ م } \\
\hline & & $\%$ & 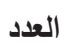 & $\%$ & 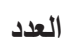 & $\%$ & العدد العد & & \\
\hline o & r,乏. & 19,0 & 11 & $r \cdot, V$ & 19 & 09,1 & 00 & تدريب المرأة الريفية علي تتفيذ بعض الصناعات & 1 \\
\hline 1 & $r, 0 \leqslant$ & Ir, & 11 & YI,, $\mathrm{V}$ & $r \cdot$ & ז7, & 71 & المساهمة في تتفيذ برامج محو أمية للمرأة الريفية & r \\
\hline$\varepsilon$ & $r, 乏 \wedge$ & $1 \leqslant, 1$ & r & $r$ r, & rt & $o v$, & or & الأسرة حملات توعية للمرأة الريفية حول تنظيم & r \\
\hline$\wedge$ & $r, r$. & $r r, q$ & rt & $r$ r,A & Y) & r.t & $\leq 9$ & تعريفية المرأة الريفية بالقواعد العامة للتغذية & $\varepsilon$ \\
\hline$\wedge$ & $r, r$. & $r, \Lambda$ & (1) & $r_{0, .}$ & rr & or, r & $\varepsilon \wedge$ & تعريف لالمرأة الريفية بأسباب سوء التغذية والآثار & 0 \\
\hline 7 & t,r & $r r, \Lambda$ & $r_{1}$ & $r,, V$ & $r$. & $00, \varepsilon$ & 01 & تعريف المرأة الريفية بأمراض سوء التغذية & 7 \\
\hline 9 & r,Yo & $r 7,1$ & $r \leq$ & $r, \wedge$ & $Y_{1}$ & 01,1 & $\varepsilon V$ & تعريف المرأة الريغية بالعادات الغذائية السليمة & $v$ \\
\hline r & $r, 01$ & $17, r$ & 10 & 17, & 10 & $T V, \varepsilon$ & Tr & تعريف المرأة الريفية بالأساليب الصحيحة لتخزين & $\wedge$ \\
\hline r & r,o. & $10, r$ & $1 \varepsilon$ & 19,0 & 11 & $70, r$ & 7. & 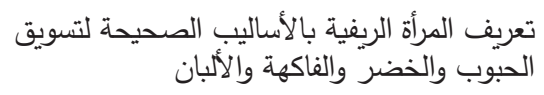 & 9 \\
\hline r & $r, 0$. & r & 10 & $\mathrm{~V}, \varepsilon$ & 17 & ז,ד & 7) & تعريف الأمرأة الريفية بأساليب تربية الطيور المنزلية & 1. \\
\hline V & r,r) & $r r, q$ & $r r$ & $r \cdot, V$ & 19 & $00, \varepsilon$ & 01 & تعريف الدارخل المرأة الريفية بأساليب ترشيد الاستهلاك & 11 \\
\hline$\wedge$ & $r, r$. & $r 0,1$ & rr & 19,0 & 11 & $00, \varepsilon$ & 01 & تعئزنف المنزل المرأة الريفية بالأساليب الصحيحة لإدارة & IT \\
\hline
\end{tabular}


الثامنة والأخيرة وقع تقييم البرامج الإرشادية المنفةة بالمنطقة

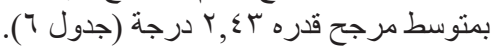

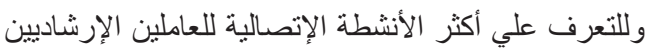

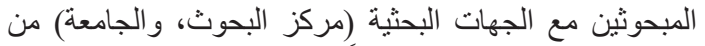
حبث معرفتهم بها مرتبة تنازلياً وفق المتوسط المبر المرجح كما في من جدول (У) علي النحو التالي: جاء في المرتبة الأولي تنفيذ اجتماعات وندوات إرشادية

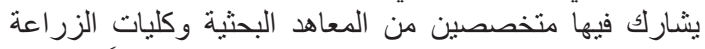

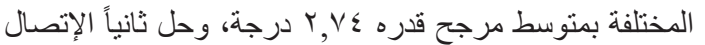

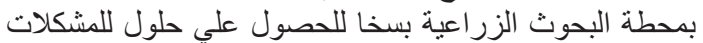

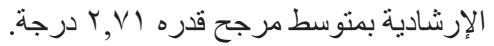

يعقبه في المرتبة الثالثة إعداد التقارير الدورية بصورة منتظمة

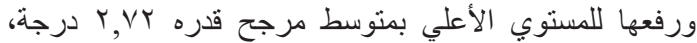

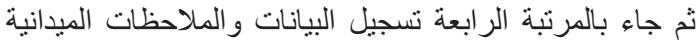

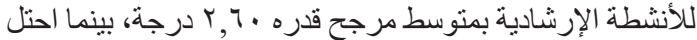

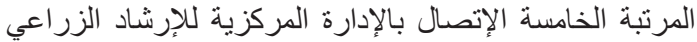

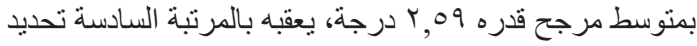

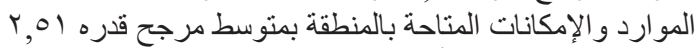

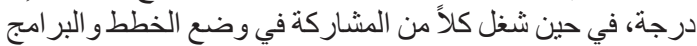

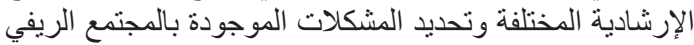

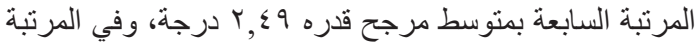

جدول 7. توزيع المبحوثين وفق معرفتهم بالأنثطة الإتصالية المتعلقة بزملاء ورؤساء العمل

\begin{tabular}{|c|c|c|c|c|c|c|c|c|c|}
\hline \multirow{2}{*}{ الترتيب } & \multirow{2}{*}{ المرجح } & \multicolumn{2}{|c|}{ لا يعرف } & \multicolumn{2}{|c|}{ إلي حـ ما } & \multicolumn{2}{|c|}{ يعرف } & \multirow{2}{*}{ الأنشطة الإتصالية } & \multirow[b]{2}{*}{ p } \\
\hline & & $\%$ & العدد العد & $\%$ & العدد & $\%$ & العدد العد & & \\
\hline r & $r, V Y$ & $0, \varepsilon$ & 0 & $1 \mathrm{~V}, \varepsilon$ & 17 & $V V, Y$ & $v_{1}$ & إعداد التقاريرِ الدورية بصورة منتظمة ورفعها & 1 \\
\hline v & $r, \Sigma q$ & $1 \cdot, 9$ & $1 \cdot$ & rq, r & rV & $09, \wedge$ & 00 & المختلفة المشة في وضع الخطط والبرامج الإرشادية & r \\
\hline $\mathrm{v}$ & $r, \varepsilon q$ & $1 \varepsilon, 1$ & 14 & $r \quad, \Lambda$ & (1) & $\pi, 1$ & $0 \Lambda$ & تحديد المشكلات الموجودة بالمجتمع الريفي & r \\
\hline$\wedge$ & $r, \varepsilon r$ & $1 \mathrm{~V}, \varepsilon$ & 17 & $r_{1}, \mathrm{r}$ & r. & $7 ., 9$ & 07 & تقييم البرامج الإرشادية المنفذة بالمنطقة & $\varepsilon$ \\
\hline$\varepsilon$ & T,, . & $9, \wedge$ & 9 & $r \cdot, \tau$ & 19 & 79,7 & $7 \varepsilon$ & تللأنشيل الإرشادية & 0 \\
\hline 7 & $r, 01$ & $1 \pi, \cdot$ & ir & $r, \Lambda$ & Yl & $T \varepsilon, Y$ & 09 & تحديد الموارد والإمكانات المتاحة بالمنطقة & 7 \\
\hline r & r,, 0 & $r, r$ & r & $\vee, 7$ & $\mathrm{~V}$ & $\wedge 9,1$ & Ar & الإتصال بمدبرية الزراعة & $\mathrm{V}$ \\
\hline 1 & $r, \wedge q$ & $1 \cdot, 1$ & 1 & $\Lambda, \vee$ & $\wedge$ & $9 \cdot, r$ & N & الإتصال بالإدارة الزراعية & $\Lambda$ \\
\hline ○ & $r, 09$ & 7,0 & 7 & $1 \leq, 1$ & 1 & $\vee q, \varepsilon$ & VT & الإتصال بالإدارة المركزية للإرشاد الزراعي & 9 \\
\hline
\end{tabular}

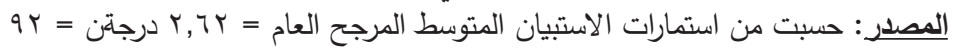

جدول v. توزيع المبحوثين وفق معرفتهر بالأنثطة الإتصالية المتعقة بالجهات البحثية (مركز البحوث، والجامعة)

\begin{tabular}{|c|c|c|c|c|c|c|c|c|c|}
\hline \multirow{2}{*}{ الترتيب } & \multirow{2}{*}{ المترسط } & \multicolumn{2}{|c|}{ لا بعرف } & \multicolumn{2}{|c|}{ إلي حد ما } & \multicolumn{2}{|c|}{ يعرف } & \multirow{2}{*}{ الأنثطة الإتصالية } & \multirow[b]{2}{*}{ e } \\
\hline & & $\%$ & العدد & $\%$ & العدد" & $\%$ & العدد & & \\
\hline r & $r, Y)$ & $\wedge, \vee$ & $\wedge$ & ${ }^{\prime}, \cdot$ & 11 & $v q, r$ & VT & 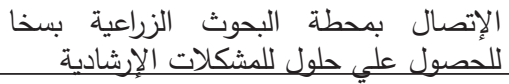 & 1 \\
\hline v & $r, r \leq$ & $17, r$ & 10 & $r r, T$ & r. & 01,1 & $\Sigma V$ & الإتشكلات لجلهامعة كفر الثيخ لعرض بعض & $Y$ \\
\hline$\varepsilon$ & $r, T r$ & $9, \wedge$ & 9 & 11,0 & IV & $v 1, v$ & 77 & دعينة الباحثين لزيارة القرية للتعرف على مشكلة & $r$ \\
\hline 0 & $r, 07$ & $1 \cdot, 9$ & 1. & $r,, V$ & $r$. & $T V, \varepsilon$ & Tr & 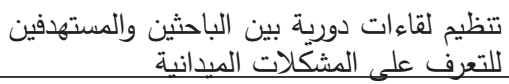 & $\varepsilon$ \\
\hline 1 & $r, V \leqslant$ & 7,0 & 7 & $1 \%$ & Ir & $\Lambda \cdot, 0$ & $V \varepsilon$ & 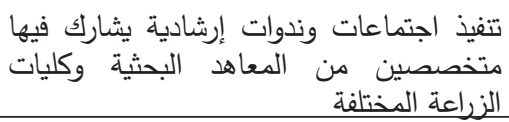 & 0 \\
\hline$\wedge$ & $r, 1 \leq$ & $r, v$ & $r$. & $r \cdot, r$ & 19 & $\varepsilon 7, V$ & $\varepsilon r$ & كفر الثبخة في تنفيذ القوافل الإرشادية لجامعة & 7 \\
\hline$r$ & T,TV & $\wedge, \vee$ & $\wedge$ & $17, r$ & 10 & vo,. & 79 & بمركز البحوث بعض الزراعدات والمحاضرات العلمية & $V$ \\
\hline 7 & r, rq & 11,0 & IV & $r r, q$ & rr & ov, 7 & or & متابعة كبر بعض الثيخ الندوات والمؤتمرات العلمية & $\wedge$ \\
\hline
\end{tabular}

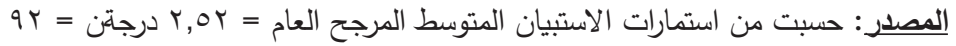

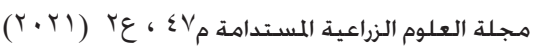


درجة، بعقبه في المرتبة الثانية التعاون مع الجهات المعنية بالبيئة

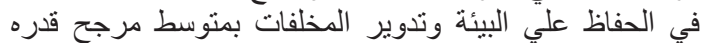

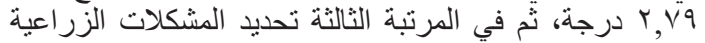

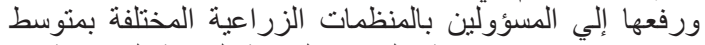

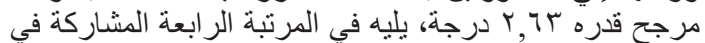

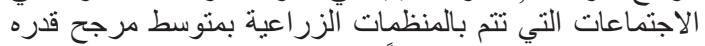

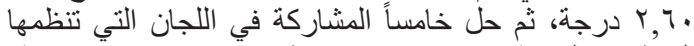

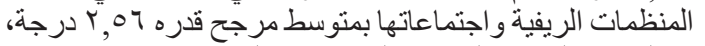

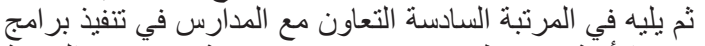

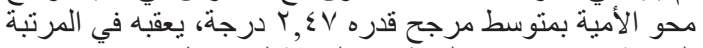

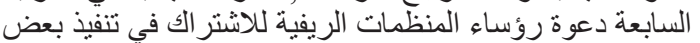

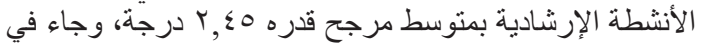

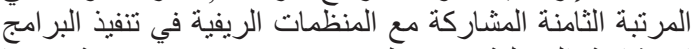

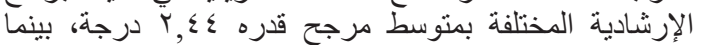

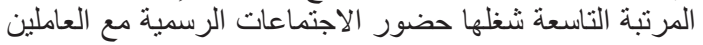

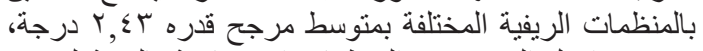

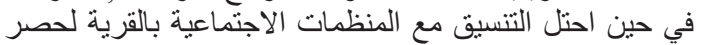

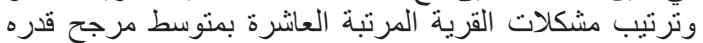

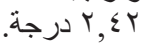

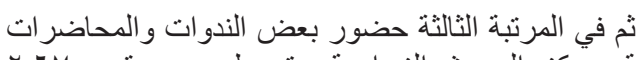

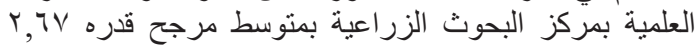

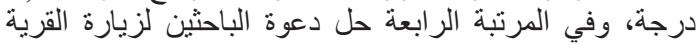

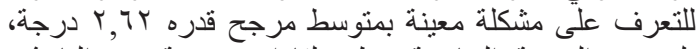

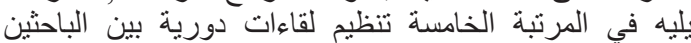

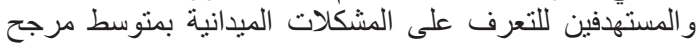

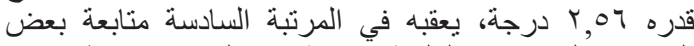

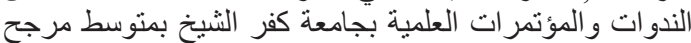

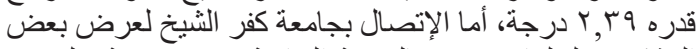

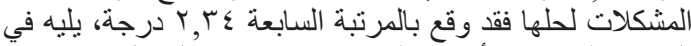

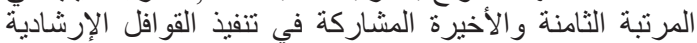

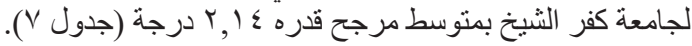
وللتعرف علي أكثر الأنشطة الإتصالية للعاملين الإرشاديين

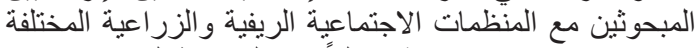

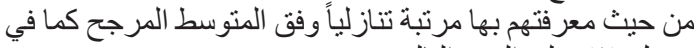

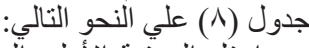

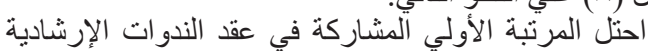

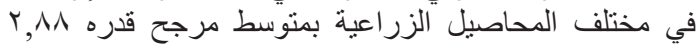

جدول ^. توزيع المبحوثين وفق معرفته بالأنثطة الإتصالية المتعلقة بالمنظمات الاجتماعية الريفية والزراعية المختلفة.

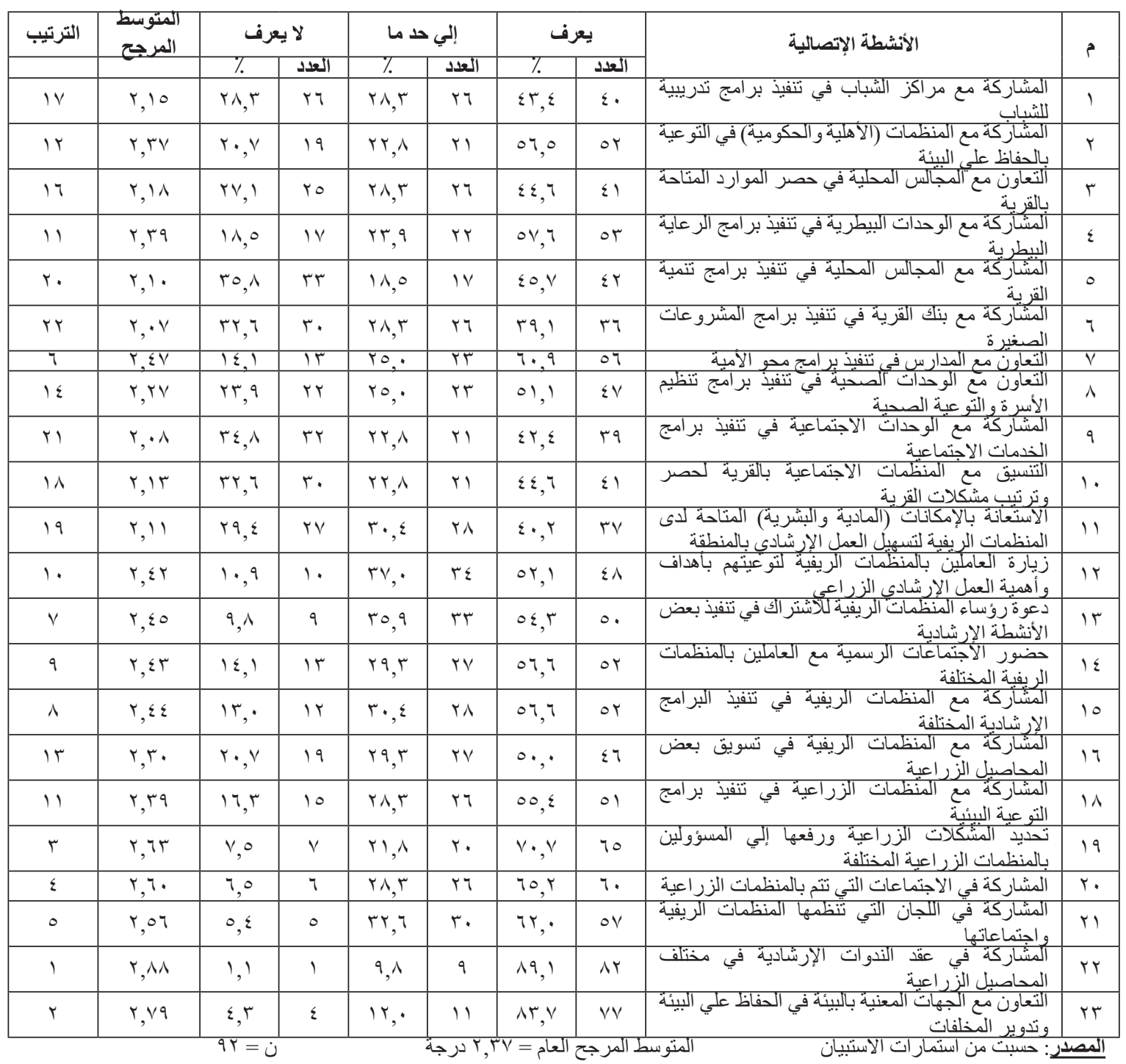


الإداري، و الإتجاه نحو العمل مع الزراع، واستخدام العاملين الإرشاديين للطرق الإتصالية الإرشادية الحديثة)وبين درجة الإنة الإنة الإنة

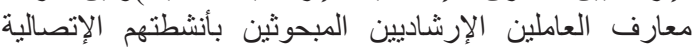

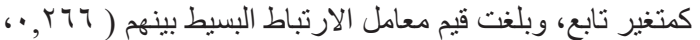

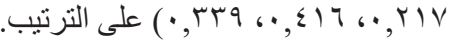

كما أوضحت النتائج بجدول (9) وجود علاقة ارتباطية

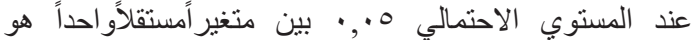
الإتصال الفعال للعاملين الإرشاديين وبين درجة معارف الإنين العاملين الإرشاديين المبحوثين بأنشطتهم الإتصالية كمتغير الإنين تابع، وبلغت الإنت

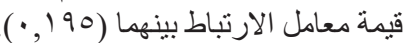

بينما لم يتبين وجود علاقة ارتباطية عند أي مستوي احتمالي بين المتغير ات المستقلة المدروسة التالية (سن المبحوث, واتلئ والمؤهل

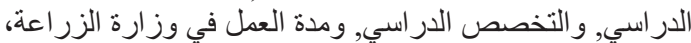

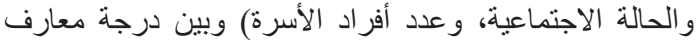

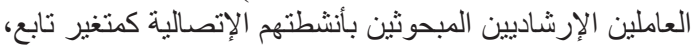

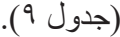

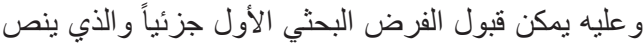

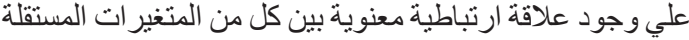

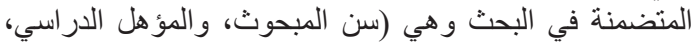

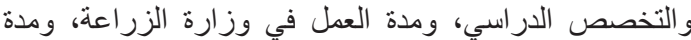

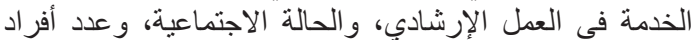

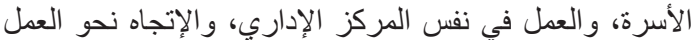

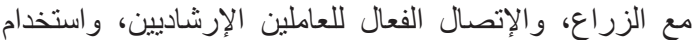

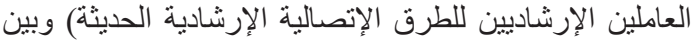
درجة معارف العاملين الإرشاديين المبحوثين بأنشطتهم الإتصالية الإنية كتغير تابع.

رابعاً: تفسير التباين بين المتغير ات المستقلة المدروسة وبين درجة المبادة معارف العاملين الإرشاديين المبحوثين بأنشطته الإتصالية الماتية:

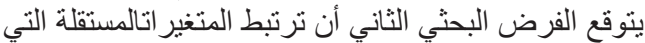

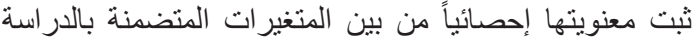
مجتمعة بدرجة معارف العاملين الإرشاديين المبحوثين بأنشطتهم بالثرات الإتصالية كمتغير تابع.

وكثفت النتائج عن أن المتغير ات المستقلة المدروسة و التي

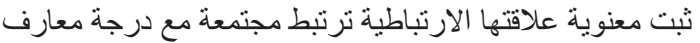

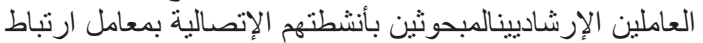

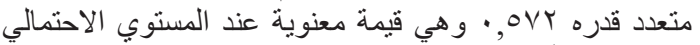

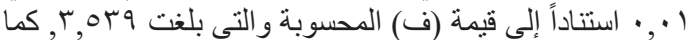

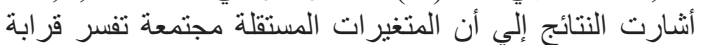

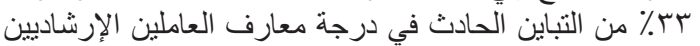

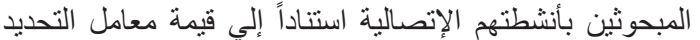

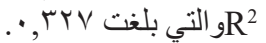

وللتعرف علي أكثر المتغيرات المستقلة تأثيراً في درجة معرفة المبحوثين بأنشطتهم الإتصالية،تم استخدام نموذج تحليل

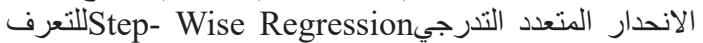

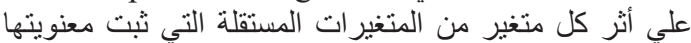

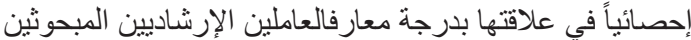

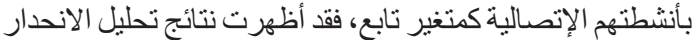

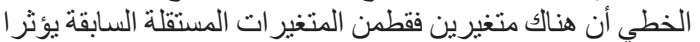
بنسب مختلفة في التباين الحادث بالمتغير التابع و هما (الاتجاه نحو التئني العمل مع الزراع، ومدة الخدمة في العمل الإرشادي).
أما المشاركة مع الوحدات البيطرية في تنفيذ بر امج الرعاية

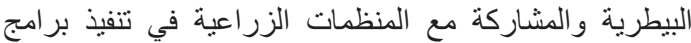

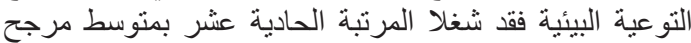

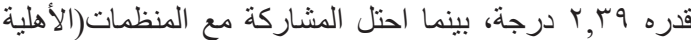

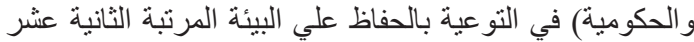

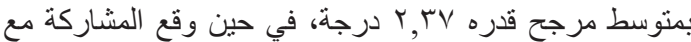

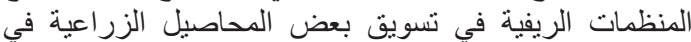

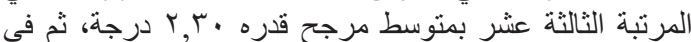

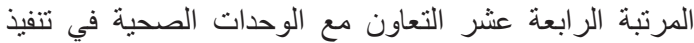

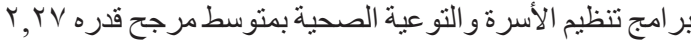

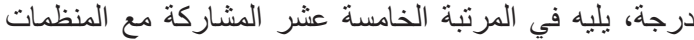

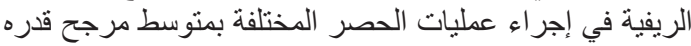

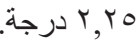

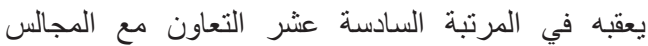

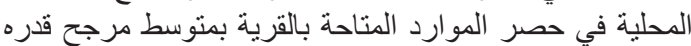

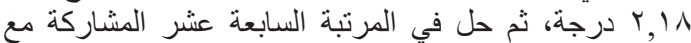

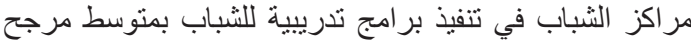

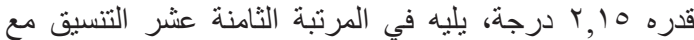

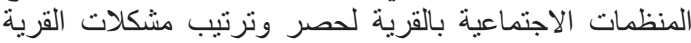

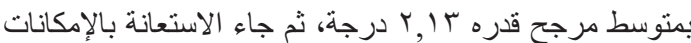

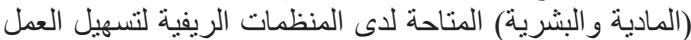

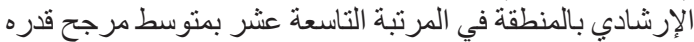

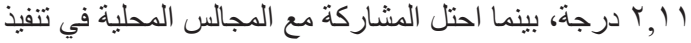

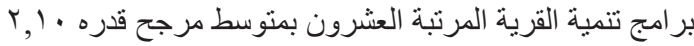

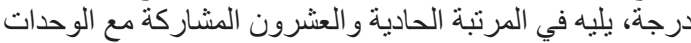

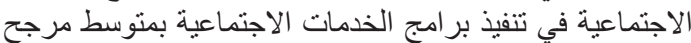

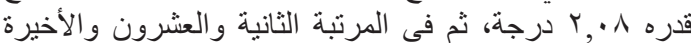

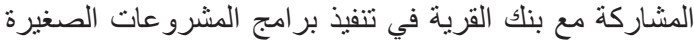

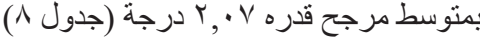

وبترتيب درجة يعارف العاملين الإرشاديينالمبحوثين بالأنشطة الإتصالية للفئات المستهدفة والبة والجهات و المنظمات الرسمية وفق المتوسط المرجح العام لكلٍ منها تبين أن: الأنشطة

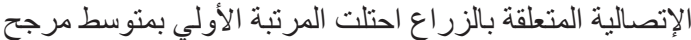
عام قدره Y, VV درجة، يليها في المرنبة الثانية الأنشطة الإتصالية

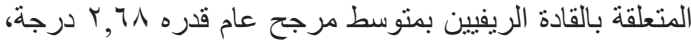

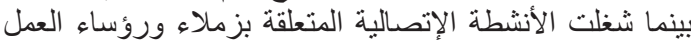

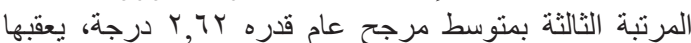
في المرتبة الرابعة الأنشطة الإتصالية المتعلقة بالثبات باتباب الريفي

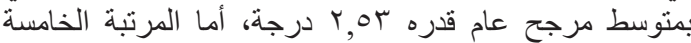
فقد احتلتها الأنشطة الإتصالية المتعلقة بالجهات برهة البحثية (مركز

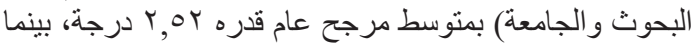

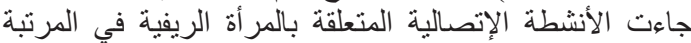

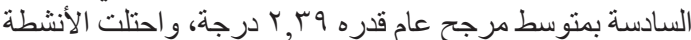

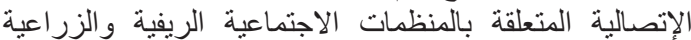

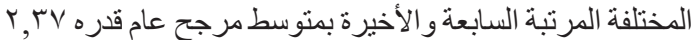

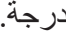

ثالثاً: العلاقات الارتباطية بين المتغيرات المستقلة المدروسة

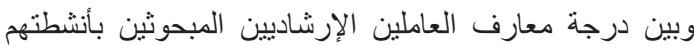
الإتصالية:

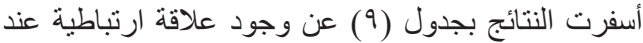

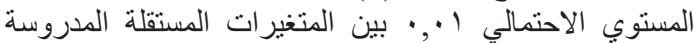
التالية (مدة الخدمة في العمل الإرشادي، والعمل في نفس المركز 


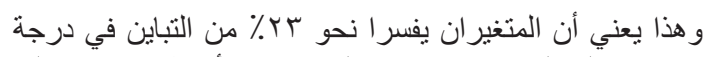
معارف العاملين الإرشاديين المبحوثين بأنشطتهم الإتصالية

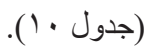

ويرتبط هذان المتغيران مجتمعين بالمتغير التابع بمعامل وبلان

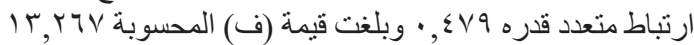

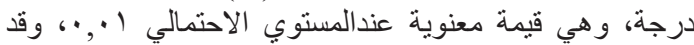

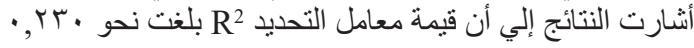

جدول 9. قيم معاملات الاتحدار الجزئي بين المتغيرات المستقلة المرتبطة معنوياً وبين درجة معارف العاملين الإرشاديين المبحوثين بأنشطتهم الإتصالية

\begin{tabular}{|c|c|c|c|c|}
\hline قيمة ت & معامل الاتحدار الجزئي & معامل الارتباط البسيط & المتغيرات المستقلة & م \\
\hline $1, \cdot 11$ & $\cdot, \wedge \vee \leq$ & $\cdot, 97$ & سـن المبحوث & 1 \\
\hline$\cdot, 0 \leq$. & $\cdot, \vee \wedge$. & $\cdot, \cdot \leq 1$ & المؤ هل الدر اسي & r \\
\hline$\cdot, \wedge \leq \uparrow$ & $7, .0 \leqslant$ & $\cdot, \mid r \wedge$ & التخصص الدر اسي & $r$ \\
\hline$\cdot, \cdot \leq$. & $\cdot, \cdot r \cdot$ & $\cdot, \cdot \leq r$ & مدة العمل في وزارة الزر اعة & $\varepsilon$ \\
\hline$* * r, Y \wedge \Lambda$ & $\cdot, 97 \leqslant$ & **, , Yฯ & مدة الخدمة في العمل الإرشادي & 0 \\
\hline$\cdot, \wedge r \leq$ & $\uparrow, \cdot \leq r$ & $\cdot, \cdot 10$ & الحالة الاجتماعية & 1 \\
\hline$\cdot,\{91$ & $1,0.0$ & $\cdot,+71$ & عدد أفر اد الأسرة & 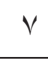 \\
\hline$\cdot, 0 \wedge 9$ & $0, \leqslant \leqslant 1$ & $* *, Y \backslash V$ & العمل في نفس المركز الإداري & $\wedge$ \\
\hline$* * \Gamma, 1)$ & $\varepsilon, \wedge 0$ & $* *, \leq 17$ & الاتجاه نحو العمل مع الزراع & 9 \\
\hline 1,707 & $1, .09$ & **., & الإرشادية الحديثة الإرشاديين للطرق الإتصالية & 1. \\
\hline $1, \leqslant$ ฯ & $r, \cdots$ & $*, 190$ & الإتصال الفعال للعاملين الإرشاديين & 11 \\
\hline
\end{tabular}

جدول • ا. النموذج المختزل للعلاقات الارتباطية والانحدارية بين المتغيرات المستقلة المرتبطة معنوياً بدرجة معارف العاملين الإرشاديين المبحوثين بأنشطتهم الإتصالية

\begin{tabular}{|c|c|c|c|c|}
\hline 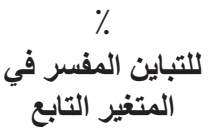 & للتباين المفسر التراكية & قيمة ت & معامل الانحـار & المتغيرات المستقلة \\
\hline iv,r & $\cdot, I V r$ & $* \varepsilon$, , $\wedge \uparrow$ & $7,1 \leq r$ & الاتجاه نحو العمل مع الزراع \\
\hline $0, V$ & $\cdot, r$. & $* r, 00 r$ & $\cdot, 907$ & مدة الخدمة في العمل الإرشـادي \\
\hline
\end{tabular}


الزر اعية في محافظة صلاح الدين، المؤتمر الدولي العلمي

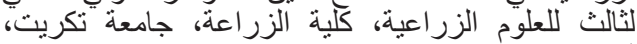

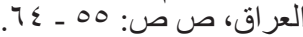

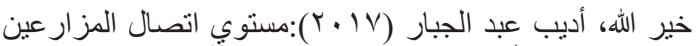

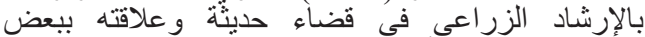

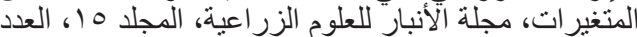

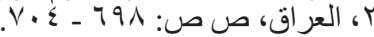

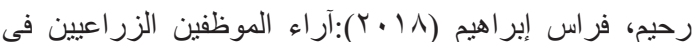

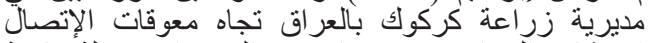

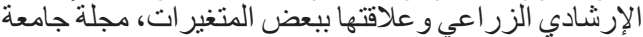

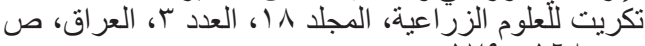
ص:

سلامة، منى فتحي (· • (Y):الآثار التعليمية للحقول الإرشادية

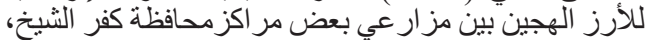
رسالة دكتور اهن، كلية الزرآ أعة، جامعة كفر الثيخ، مصر. سيد أحمد، غريب محمد (99 199):تصميم وتنفيذ البحث الاجتماعي، دار المعرفة الجامعية، الإسكندرية، مصر.

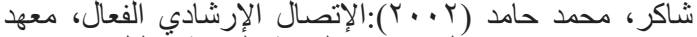
بحوث الإرشاد الزراعي والتنمية الريفية، دليل مرجعي، الزئية مركز البحوث الزراعية، الجيزة، مصر الزئية

صالح، صبري مصطفى، ومحمد عمر الطنوبي، وسهير عزمي الزئي

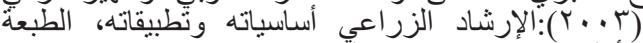
الأولي، مركز الإسكندرية للكتاب، الإسكندرية، مصر.

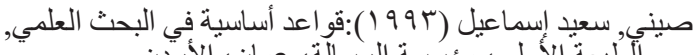
ألّبعة الأولي، مؤسسة الرسالة، عمان، الأردن.

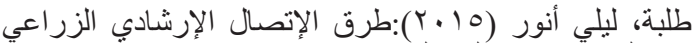

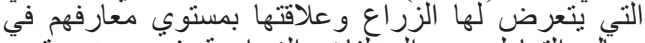

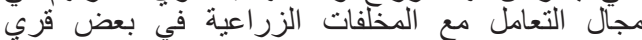
محافظتي الإسكندرية والبحيرة، مجلة الإسكندرية البكاية للتبادل

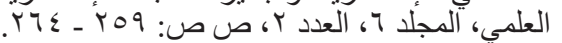

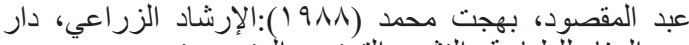

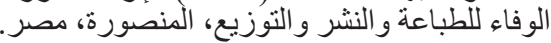

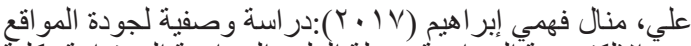

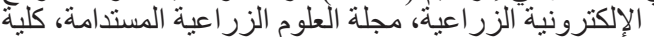

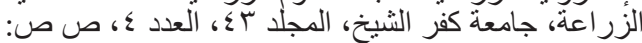
19. - 1Vo

عمر، أحمد محمد (99 199):الإرشاد الزراعي المعاصر, مصر للخدمات العلمية، القاهرة، مصر الإنداد الحمر

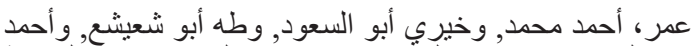

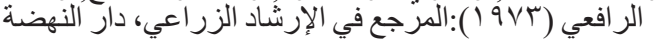

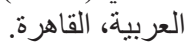

كعكه، وليد عبد الغني (7 ( • ب):تقييم استخدام المرشدين الزر اعبين

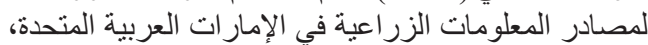

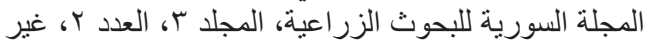

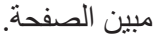

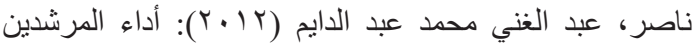

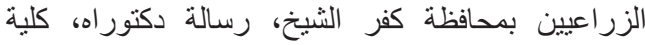
الزر اعة، جامعة كفر الثيخ، مصر. نوناكا وتاكوشي (990 199):صناعة المعرفة، جامعة أوكسفورد، نيويورك، الّولايات المتحدة الأمريكية.

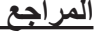

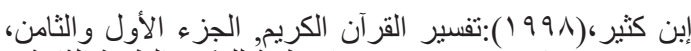
تحقيق سامي محمد سلامه، دار طيبة للنشر ، الطبعة الثانية.

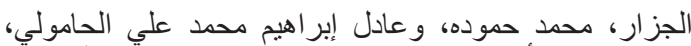

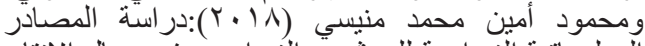
المعلوماتية الزر اعية للمرشدين الزر اعيين في مجال الإنتاج

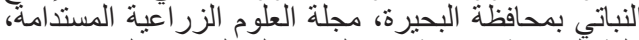

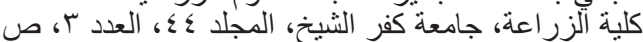
ص: $1 \cdot v-90$

الحامولي، عادل إبر اهيم محمد علي، ومنال فهمي إبراهيم علي، إني،

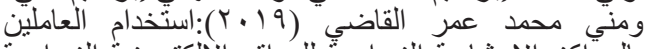
بالمر"اكز الإرشادية الزر اعية للمواقع الإلكترونية الزراعية العاعية

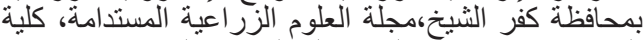

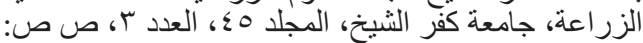
r) - r.

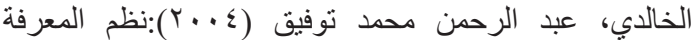

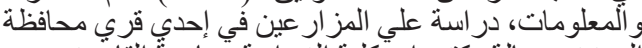

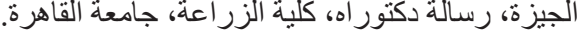

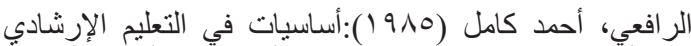

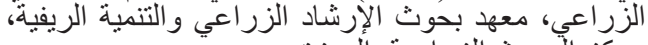

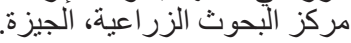

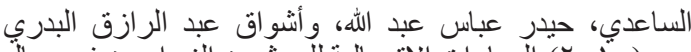

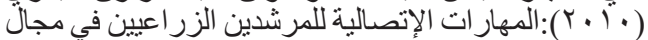

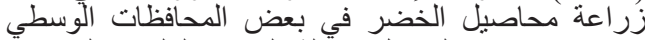

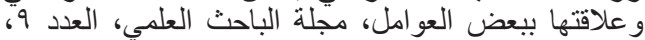

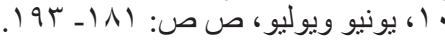

الثافعي، عبد العليم أحمد، وأحمد محمد الذهبي، ورضا الإندا حسن

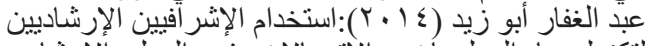

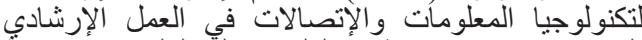

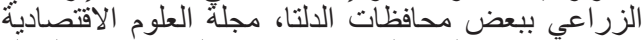

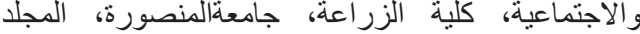

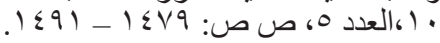

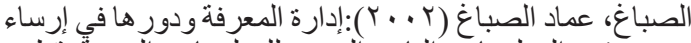

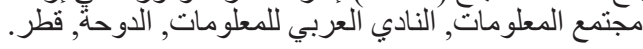

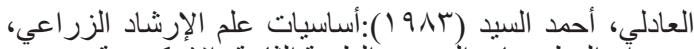

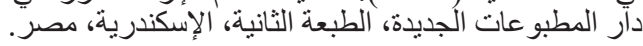

بدير، سهير(919 (1):البحث العلمي, دار المعارف, القاهرة،

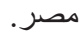

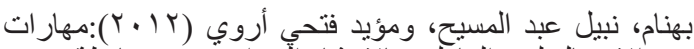
الإتصال لاعي العاملين بالإرشاد التزر اعي في محافظة نينة نينوي

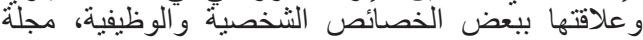
زراعة الر افدين، المجلد ·ـ؛، العدد ب، العراق، غير مبين الصفحة.

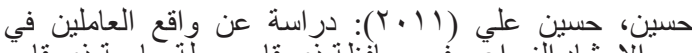

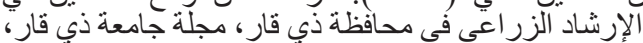

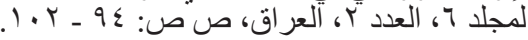

حفني، منصور أحمد محمد، وسامي محمد عبد الحميد دراز

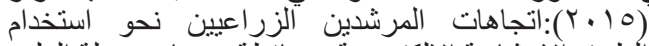

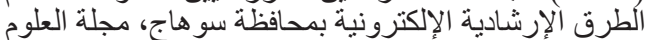

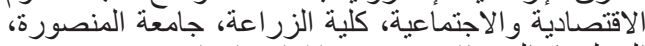

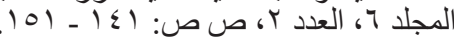

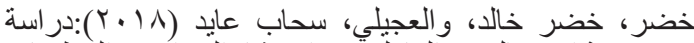
علاقة الإتصال بين العاملين في الإرشاد الزر اعي و التنظيمات 


\title{
Knowledge of The Extension Workers of Their Communication Activities at Kafr El-Sheikh Governorate
}

\author{
Adel I. M. A. Elhamoly, Ahmad M. A. Abdallah, Abdaleem S. A. Elshafay and \\ Ezzat M. Megahed \\ Dept. of Agric. Economics, Fac. Of Agric., Kafrelsheikh University. Agric. Research \\ Center, High student
}

$\mathbf{T}$

HE research mainly aimed to identify the degree of knowledge of the extension workers about their communication activities at Kafr El-Sheikh Governorate. The research data were collected from all the respondents by the personal questionnaire. They were analyzed by using several statistical tools as: percentage, frequencies, means, standard deviation, the simple \& multiple correlation coefficients, and the partial \& multiple regression coefficients. The most important results included the degree of the respondents' knowledge of communication activities related to farmers ranked first with 2.77 degrees, followed by communication activities related to rural leaders with 2.68 , then the communication activities related to colleagues and work leaders ranked third with 2.62 degrees, followed by communication activities related to rural youth with 2.53 degrees, then communication activities related to research institutions (Research Center and the University) with 2.52 degrees, then communication activities related to rural women 2.39 degrees, and finally the communication activities related to various rural and agricultural social organizations with of 2.37 degrees. The most important variables affecting the dependent variable were: use of the respondents for modern indicative communication methods, and the effective communication of the extension workers.

Keywords: Knowledge; Activities; Communication; Farmers; Rural leaders; Organizations. 